\title{
Detecting marine hazardous substances and organisms: sensors for pollutants, toxins, and pathogens
}

\author{
O. Zielinski ${ }^{1}$, J. A. Busch ${ }^{1}$, A. D. Cembella ${ }^{2}$, K. L. Daly ${ }^{3}$, J. Engelbrektsson ${ }^{4}$, A. K. Hannides ${ }^{5}$, and H. Schmidt ${ }^{6}$ \\ ${ }^{1}$ Institute for Marine Resources, Bremerhaven, Germany \\ ${ }^{2}$ Alfred Wegener Institute for Polar- and Marine Research, Bremerhaven, Germany \\ ${ }^{3}$ College of Marine Science, University of South Florida, St. Petersburg, FL, USA \\ ${ }^{4}$ Department of Chemistry, University of Gothenburg, Sweden \\ ${ }^{5}$ Department of Fisheries and Marine Research, Nicosia, Cyprus \\ ${ }^{6}$ Institute for Optics and Atomic Physics, Technical University Berlin, Germany
}

Received: 29 April 2009 - Published in Ocean Sci. Discuss.: 14 May 2009

Revised: 16 August 2009 - Accepted: 25 August 2009 - Published: 11 September 2009

\begin{abstract}
Marine environments are influenced by a wide diversity of anthropogenic and natural substances and organisms that may have adverse effects on human health and ecosystems. Real-time measurements of pollutants, toxins, and pathogens across a range of spatial scales are required to adequately monitor these hazards, manage the consequences, and to understand the processes governing their magnitude and distribution. Significant technological advancements have been made in recent years for the detection and analysis of such marine hazards. In particular, sensors deployed on a variety of mobile and fixed-point observing platforms provide a valuable means to assess hazards. In this review, we present state-of-the-art of sensor technology for the detection of harmful substances and organisms in the ocean. Sensors are classified by their adaptability to various platforms, addressing large, intermediate, or small areal scales. Current gaps and future demands are identified with an indication of the urgent need for new sensors to detect marine hazards at all scales in autonomous real-time mode. Progress in sensor technology is expected to depend on the development of small-scale sensor technologies with a high sensitivity and specificity towards target analytes or organisms. However, deployable systems must comply with platform requirements as these interconnect the three areal scales. Future developments will include the integration of existing methods into complex and operational sensing systems for a comprehensive strategy for long-term monitoring.
\end{abstract}

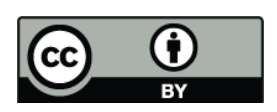

Correspondence to: O. Zielinski

(oliver.zielinski@imare.de)
The combination of sensor techniques on all scales will remain crucial for the demand of large spatial and temporal coverage.

\section{Introduction}

The quality of marine environments is influenced by a range of anthropogenic and natural hazards, which may adversely affect human health, living resources and the general ecosystem. The focus of this review is on biological marine hazards, including those produced by organisms or the organisms themselves, and on chemically mediated deleterious effects, rather than on physical hazards (rogue waves, tsunamis, storm surge, meteorological effects, etc.). Major components of such bio-hazards are typically endogenous to marine systems, but may also be contributed from freshwater aquatic and terrestrial habitats via run-off and coastal erosion. Identification of types of hazards and their temporal and spatial scale are crucial for an analysis of the associated risks. In this review, we address the assessments of ecological status and the protection and restoration of ecological potential of habitats. These issues are regulated by law under global, regional or national statutes, such as the EU Water Framework Directive (WFD) (2000/60/EC), the EU Marine Strategy Framework Directive (MSFD) (2008/56/EC), and the US Federal Water Pollution Control Act (Clean Water Act, CWA) of 1948 and its amendments (33 U.S.C. 12511376).

Published by Copernicus Publications on behalf of the European Geosciences Union. 
One goal of the marine science community has been to detect hazardous substances and organisms and to monitor related parameters in the ocean to improve understanding of critical processes and to prevent and mitigate adverse effects. Significant advances in the detection and analysis of hazards have been achieved in recent years, in particular in expanding the temporal and spatial scales of observational technologies and in improving resolution. These monitoring techniques are, in most cases, complementary to methods applied to discrete point-source samples. A close cooperation between remote- and in situ disciplines has also emerged, if somewhat belatedly. During the last decade, a range of global and regional monitoring programs have been developed to protect human and environmental health and prevent economic losses caused by marine hazardous substances and organisms in an integrated manner. Amongst these programs are the following: 1) Global Ocean Observing System (GOOS, 2008), 2) Global Ecology and Oceanography of Harmful Algal Blooms (GEOHAB, 2008), 3) Harmful Algal Bloom Forecasting System (NOAA, 2008a), 4) CoastWatch (NOAA, 2008b), and 5) United Nations Environment Program (UNEP) on Global Monitoring for Persistent Organic Pollutants (POPs) (UNEP, 2004), as well as monitoring in accordance with regional sea conventions such as OSPAR (OSPAR, 2009), and HELCOM (HELCOM, 2009).

To tackle extant and emerging environmental problems, flexible approaches and methodologies must be linked with decision-making strategies of managers. Ecological risk assessment is currently undergoing a shift from the evaluation of particular health impacts, often on a small scale in a specific environment, towards more complex assessments of whole populations and communities across ecologically meaningful landscapes on larger scales (Landis, 2003; Hope, 2006). This conceptual approach was designed primarily with terrestrial "landscapes" in mind, but it is no less valid for consideration of "seascapes", albeit that the fluxes, dynamics, and community structures are somewhat different in the sea. Increasingly, remote observations will be performed on an operational basis from a variety of in situ platforms and enabling technologies, including profiling moorings and floats, autonomous underwater vehicles (AUVs), gliders, drifters, ships-of-opportunity, and nodes attached to cable networks. Since successful remote ocean operations for marine hazards fundamentally depend on the sensing techniques, we have to examine the state-of-technology and derive demands for upcoming methodologies, sensors, and sensor systems.

Sensors may be generally characterized as devices that capture and transduce a signal related to the presence and/or concentration of a compound or organism, including related physical properties, which can then be stored or transmitted to a receiver at a different location. The captured signal can then be related to biological, chemical, or physical processes affected by or affecting the compounds or organisms detected. "Smart sensors" additionally comprise the ability of the sensor to process and evaluate the captured signal to yield information upon which the receiver or the sensor platform can directly respond.

A variety of platforms are needed to support sensing systems in the ocean, including multiplex and integrated observational technologies. Fixed-point profiling moorings are essential to resolve a wide range of temporal variability (short-lived episodic events, subtle changes over decades, etc.) of physical, chemical, and biological processes that occur between the sea surface and the sea floor. Mobile platforms (floats, gliders, AUVs) with appropriate sensors provide measurements of spatial variability to complement the fixed sites. Satellites can yield broad spatial synoptic measurements of the surface ocean, but are of limited use in the vertical dimension.

A vast number of articles have been published on the detection of hazardous substances and organisms. A recently published comprehensive volume on observational technologies for coastal ecosystems, with a focus on Harmful Algal Blooms (HABs) (Babin et al., 2008) is illustrative of the rapid advancements in such fields. The coverage of all hazards and upcoming technologies in this active field of development would have to be accomplished separately. Rather than providing a detailed review of all groups of hazardous substances and organisms, including all possible sensors, here we restrict our purview to advanced techniques for detection of marine pollution, toxins, and pathogens in the ocean, with a focus on sensors applicable for remote deployment.

\section{Marine health hazards}

Hazardous substances and organisms in marine waters may derive from anthropogenic or natural sources. In this review we distinguish between anthropogenic marine pollution (MP), natural marine toxins (MT), and pathogenic agents (PA) (Fig. 1). Unfortunately these categories are not clear cut - formation of many marine pollutants is facilitated by the combination and transformation of anthropogenic components with naturally occurring substances. Furthermore, hazardous "natural" occurrences of toxic organisms (e.g., HABs) or bacterial and viral pathogens may be stimulated by human activities, such as sewage inflow and eutrophication or long distance human-mediated transport, as in ship ballast water. Finally, natural pathogenic organisms can be enhanced in diversity and biogeographical extent through human interventions such as agricultural run-off and improper sewage treatment. It is, therefore, unwise to treat these phenomena as unrelated events for observational and management purposes.

By consensus MP is considered to be derived exclusively from human activities. The term pollution is defined by GESAMP (Joint Group of Experts on the Scientific Aspects of Marine Environmental Protection, 1983) as: 


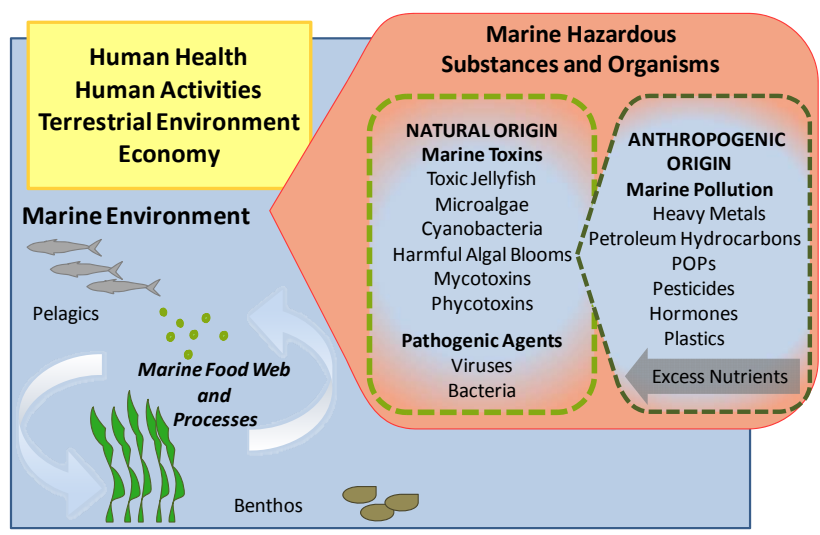

Fig. 1. Classification of marine hazards of anthropogenic and natural origin, as structured within this review, and schematic of marine and terrestrial systems imperilled by these harmful substances and organisms. Marine systems are sensitive to bioaccumulation in food webs.

"... the introduction by man, directly or indirectly, of substances or energy into the marine environment (including estuaries) resulting in such deleterious effects as harm to living resources, hazards to human health, hindrance of marine activities, including fishing, impairment of quality of use of seawater, and reduction of amenities."

According to the EU WFD and the US CWA, priority substances that represent a significant risk to or via the aquatic environment range from toxic metals to organic contaminants, such as persistent hydrocarbons, organochlorine compounds and pesticides, as well as organometallic compounds. In this review of marine sensing technologies, we examine the broad range of MP divided into sub-categories: heavy metals, including cadmium, mercury, lead, copper, and radionuclides; polyaromatic hydrocarbons (PAHs), also referred to as oils or polycyclic aromatic hydrocarbons, dispersed in water or as a surface layer; persistent organic pollutants, such as polychlorinated biphenyls (PCBs), tributyltin (TBT) compounds, pesticides, dioxins and furans, and also excess macronutrients, such as nitrate, ammonia, and phosphate. These nutrients occur naturally in the ocean and are critical to ecosystem function, but are considered pollutants when land-based nutrients entering watersheds and estuaries exceed natural levels, and stimulate excessive primary productivity - a process termed eutrophication (GESAMP, 1990). An additional class of pollutant is constituted by hormones, such as estradiol, estrone, and ethinylestradiol, contributed largely from anthropogenic sources such as domestic sewage and run-off from waste originating as hormone supplements or birth control agents, or agriculture. High concentrations of certain hormones in aquatic systems are responsible for developmental anomalies, e.g., change of sex in fish (Christiansen et al., 2002).
When considering man-made marine pollutants, the issue of waste disposal and long degradation periods for discarded plastics is of increasing concern. Plastics absorb PCBs in aqueous media (Endo et al., 2005; Rios et al., 2007). A correlation between ingested plastic and polychlorinated biphenyls (PCBs) has already been detected over two decades ago in the great shearwater Puffinus gravis (Ryan et al., 1988). Plastic particle uptake has also been observed in holothurians (i.e., sea cucumbers) (Graham and Thompson, 2009), therefore leading to accumulation in the food web. Plastic particles could conceivably also influence the spreading of indigenous HABs as a vector for microalgal dispersal (Masó et al., 2003).

Health hazards with a natural origin comprise both MT and PA, although recent observations indicate an increased prevalence and distribution due, at least partially, to anthropogenic influences on the marine environment (Anderson et al., 2002). A large number of marine animals from many different phyla, including certain snails, jellyfish, sea anemones, sea urchins, sponges, and fish, etc. produce highly bioactive substances, including potent toxins and venoms for prey capture or defence. These substances can also be hazardous to human health. Because the effects are extremely localized and the toxins themselves cannot usually be monitored with in situ or remote sensors, they are not dealt with in detail in this review.

An exception should be made for toxic jellyfish (medusae and comb-jellies), which can be potentially monitored by optical sensors when present as mass occurrences ("jellyfish blooms"). Swarms of poisonous and nuisance jellyfish species are responsible for world-wide seasonal beach closings, power plant shut-downs, and even fish-farm cage destruction (e.g., Graham et al., 2001; Mills, 2001). Although the exact reasons for jellyfish blooms are incompletely understood, these mass occurrences are likely to continue unabated in the future and to pose the same if not increasing hazards to many human activities, especially in the coastal zone.

Our focus here on MT comprises biotoxins synthesized by living organisms, with emphasis on toxins produced by microorganisms, such as microalgae, fungi, and bacteria, including cyanobacteria. These MTs are widely associated with contamination of seafood. The most widespread classification of these microorganism-derived toxins linked to seafood poisoning is based on associated toxin syndromes (Campás et al., 2007), e.g., okadaic acid and dinophysistoxin analogues causing diarrheic shellfish poisoning (DSP); saxitoxin and related derivatives causing paralytic shellfish poisoning (PSP); domoic acid associated with amnesic shellfish poisoning (ASP); brevetoxins causing neurologic shellfish poisoning (NSP); azaspiracids causing azaspiracid shellfish poisoning (AZP); ciguatoxin and maitotoxin analogues linked to ciguatera fish poisoning (CFP); and tetrodotoxin causing pufferfish $(f u g u)$ poisoning (Geistdoerfer and Goyffon, 2004; Campas et al., 2007). 
Human illness caused by marine toxins can also be divided into their primary transvectors - those associated with seafood consumption, and those due to exposure to water (or aerosols) containing toxins. These human health effects are highly diverse, ranging from mild to acute (even fatal) especially when neurotoxins are involved, and can include nausea, neurological disturbances, paralysis, short term memory loss, fevers, ear and eye irritation, and pulmonary consolidation. Longer term exposure may be associated with kidneyand liver damage, even resulting in carcinogenesis and/or tumour promotion (for references see Codd et al., 2005).

Most toxins associated with marine microorganisms are naturally produced by microalgae, including the prokaryotic cyanobacteria ("blue-green algae"). There are also occasional reports of mycotoxins in the marine environment, such as those of the toxic fungus Aspergillus fumigatus, which can accumulate in mussels (Grovel et al., 2003). Toxins of algal origin (phycotoxins) may be transferred through the food chain via the consumption of toxic microalgae and then can accumulate in higher trophic levels (fish, marine mammals, seabirds) with devastating consequences. As well, these toxins in seafood pose a health risk for human consumers. Phycotoxins in the marine environment regularly lead to restrictions on commercial and recreational shellfish harvesting and negatively impact tourism and public health resulting in high economic losses each year. Cyanobacterial toxins in fresh and brackish water are another critical and emerging problem, with evidence of effects on adjacent linked marine ecosystems related both to toxicity and high biomass production.

The term HAB - Harmful Algal Bloom - is often applied operationally to algal occurrences that cause harm through the production of toxins and/or by excessive accumulation of biomass - but not all HABs meet both criteria (Anderson et al., 2002; Máso and Gárces, 2006). Blooms are generally characterized by development, maintenance, and decline phases. The detection of such events occurs mainly during later development and maintenance stages when significant biomass and/or toxic effects are present; early warnings of impending events are thus rare and bloom prediction and modelling remains a major challenge that is being addressed in only a few key areas (e.g., the Gulf of Maine, reviewed by Anderson et al., 2005). High biomass accumulation alone may lead to environmental damage, such as hypoxia, anoxia, and harmful shading of underlying vegetation, such as seagrass beds and corals. Furthermore, certain toxins, including some from cyanobacteria, can persist in the water phase after extracellular release (Lawton et al., 1994), thus the absence of the bloom does not necessarily indicate absence of toxins.

A pathogenic agent is defined as "any organism, which in living on or within another organism (the host) causes disease in the host" (FAO, 1998). Agents of waterborne diseases include viruses, bacteria, and protozoa (Gerba, 1996). Although many species of cyanobacteria ("blue-green algae") and some free-living marine protists (eukaryotic microalgae and protozoa) are responsible for waterborne diseases associated with the production of phycotoxins, they are not intrinsic pathogens to mammalian hosts and, therefore, will be considered under the HAB topic for purposes of this review. Nevertheless, there is evidence of correlations in the occurrence of algal blooms and viruses, stressing the need of process monitoring and cross-linking fields of research.

Some pathogens, such as the cholera bacterium, Vibrio cholera, occur naturally in marine waters, whereas others, e.g., from faecal contamination sources, may have only limited survival periods in the marine environment. Generally, the survival of bacteria depends on factors such as water quality, nutrient supply, salinity, exposure to sunlight (ultraviolet radiation) (Johnson et al., 1997), as well as grazing pressure (Worden et al., 2006). Human exposure pathways include head or face immersion, swallowing water, or entering water up to or beyond waist level (WHO, 2001), as well as the consumption of contaminated seafood. Increasing evidence is given for a proportional increase of associated infection rates to the level of pollution (Cabelli et al., 1982; Cheung et al, 1990; Corbett et al., 1993; Kay et al., 1994). Consequences of pathogen-contaminated waters frequently include gastroenteritis (WHO, 2001). Further symptoms and syndromes associated with pathogenic bacteria and protozoa may include: skin rashes, fever, and acute febrile respiratory illnesses (AFRI) (Fleisher et al., 1996a), salmonellosis, meningo-encephalitis, cryptosporidiosis, and giardiasis (Prüss, 1998). The risk of infection is determined by type of exposure, as well as type and concentration of pathogen. There are also economic losses due to the closure of shellfish fisheries and recreational areas. The recommended indicator for human pathogens in marine waters and gastrointestinal symptoms are faecal streptococci/enterococci bacteria (WHO, 2001). However, there is no worldwide agreement on best indicators of public health risks - the US monitors enterococcus or coliform bacteria, and Hong Kong tracks the bacterium Escherichia coli, whereas the UK monitors fecal streptococci. Unfortunately, indicator bacteria do not generally mirror the human enteric virus or bacterial distribution in seawater (Jiang et al., 2001).

\section{Detection of health hazards: status and developments}

The health hazards described above can be classified based on source of origin: a) point sources, such as discharges from urban waste waters, oil spill, or aquaculture; b) diffuse sources, like losses from agriculture or leakages; and c) spread sources, such as the atmospheric deposition on water bodies. This areal dependence on the origin of the potential hazards introduces a spatial dimension that can also be transferred to the corresponding sensing technologies. However, there is a reciprocal relationship in the spatial coverage of a research area of interest and the information depth attained by the majority of sensor methodologies associated to the 
level of areal coverage (Fig. 2). The coverage of a large area is of importance as well as precise measurements of a smaller "pixel". Subsequently, we review the state-of-technology for the detection of marine hazards following this area-approach, from large to small scales.

\subsection{Status of sensor techniques with decreasing spatial coverage}

\subsubsection{Detection on a large scale: remote sensing}

Remote sensing techniques are required to obtain broad spatial synoptic coverage of the ocean surface. In general remote sensing is the detection and identification of phenomena at a distance from the object of interest using human capabilities or special sensors. Modern remote sensing instruments are normally based on optical, electronic or, less frequently, chemical techniques. During the last few decades, many improvements have been achieved in the development of new sensors and in the improvement of existing sensors and their application (Bonn agreement Aerial Surveillance Handbook, 2007).

Remote sensing of the ocean on a larger scale is commonly, though not exclusively, applied from above the water surface via satellite or aircraft. Most wavelengths for optical or radio-sensing techniques are strongly attenuated in seawater, which prohibits a deep penetration of the water column, and, thus, are limited to sensing the surface layer of the ocean. Satellites can detect marine surface films, for example those generated by oil-spills; however, any sub-surface blooms, such as those of harmful algae, remain undetected, if low water transparency prohibits upwelling radiation from the relevant depths.

Other limitations of remote sensing are its dependency on the radiative transfer within the atmosphere, which is especially important for optical sensors. This critical feature also highlights that calibration and validation exercises are imperative. Another limitation is the restricted availability of remote optical sensing data due to cloud cover and orbital path and temporal coverage in the case of satellite-borne systems. Similar constraints may also affect the availability of airborne remote sensing data, which depends on the range, technical status, and obligations of the carrier platforms (Zielinski et al., 2001).

Remote ocean sensors, in general, require a change in the absorption, scattering, and/or reflection of water for a given wavelength, using either natural (denoted as passive sensing) or artificial (active sensing) illumination sources. Airborne sensors basically draw on the same techniques developed for satellite observations, reducing the atmospheric influences by operating at lower altitudes, but concurrently reducing their aerial coverage. The increased flexibility and mobility of airborne sensors makes them a prominent choice for surveillance tasks and supporting actions, e.g., to complement shipboard observations. Here we examine satellite and

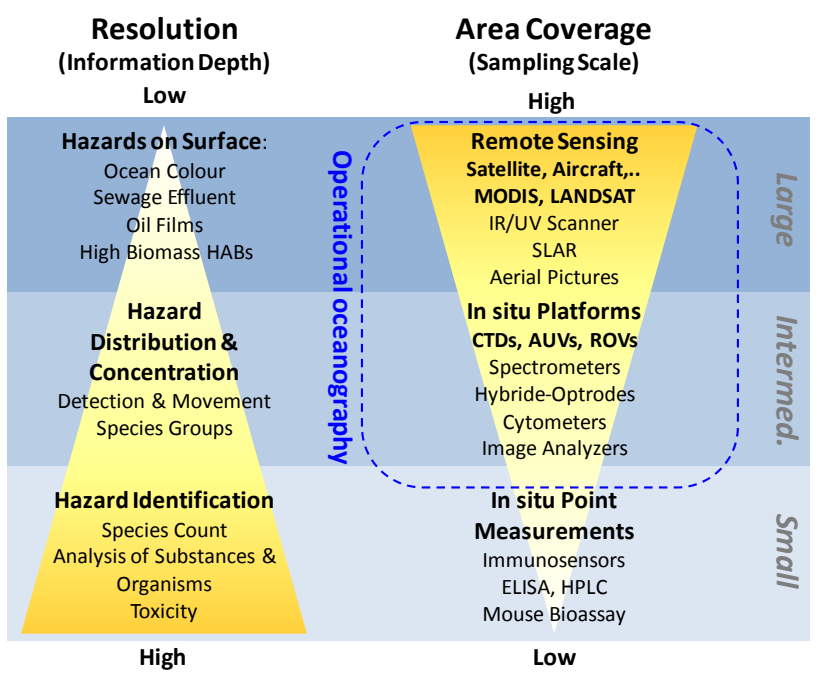

Fig. 2. The reciprocal dependency between sensor sampling resolution and sampling area influencing the extent to which information on hazardous substances and organisms in marine environments can be obtained on large-, intermediate-, and small-scales. Illustrative examples of technologies are provided.

airborne sensors as remote sensing systems and discuss existing approaches being used to address the classes of marine hazards described in Sect. 2.

\section{Marine Pollution (MP)}

MP such as caused by heavy metals and radionuclides is not directly detectable in seawater from satellite or airborne remote sensing instruments, since the pollutants are low in concentration and the known detection methods are not transferable to these remote platforms. Nevertheless, other matrices including sewage effluents can serve as indirect indicators of certain MP at large scales, whereby optical detection is achieved, e.g., by increases in turbidity or coloured dissolved organic matter (CDOM) concentrations. This also holds true for most of the persistent organic pollutants, except for petroleum hydrocarbons, for which highly specific wavelength-dependent remote sensing equipment has been developed, especially for airborne oil-spill surveillance.

During the last two decades, airborne remote sensors have evolved into common instruments for the operational surveillance of oil pollution. The most common sensor arrangements include a SLAR (side-looking airborne radar) and an IR/UV (infrared/ultraviolet) line scanner. Whereas the former sensor is used for far-range detection of pollution, the latter is especially designed to locally characterize oil spills. In addition to this standard there are sophisticated sensors, such as the laser fluorosensor (LFS) or the microwave radiometer (MWR) that allow an advanced analysis of oil spills for the remote identification of oil species and the estimation 
of film thickness (Hengstermann and Reuter, 1990; Grüner et al., 1991; Zielinski, 2003; Zielinski et al., 2006a). In addition, the laser fluorosensor may be used for hydrographic measurements of chlorophyll or CDOM (Browell, 1977; Hoge and Swift, 1983; Zielinski et al., 2001).

Satellite detection of oil spills is mainly based on radar/microwave observations, although both optical and laser induced illumination technologies have been applied (Gade, 2006). The optical properties of nutrients such as nitrate or ammonia are not accessible in the visible or infrared spectra and, therefore, not detectable directly from satellites. Again, as a guide for large-scale monitoring of certain MPs, the effects of excess nutrient concentrations contributed by sewage and river runoff in coastal areas leading to algal blooms can be detected remotely via increased chlorophyll, or other pigment-linked biomass as a proxy for high nutrients.

\section{Marine Toxins (MT) and mass occurrence of toxigenic organisms}

The presence of toxins in the water column or within marine organisms is not detectable by remote sensing since their concentrations and optical properties do not provide significant changes neither in ocean colour nor in other electromagnetic features. However, remote sensing provides for detection of mass aggregations (blooms or swarms) of biotoxin-bearing organisms. For example, the location and mass characteristics of large aggregations of the jellyfishes, e.g. Rhizostoma octopus, Cyanea capillata, and Chrysaora hysoscella, have been identified via aerial surveys (Houghton et al., 2006). Such successful applications of remote detection methods provide a means of monitoring potential primary transvectors of toxins.

Whereas toxins do not change the optical properties of seawater, high biomass algal blooms certainly do so, and can be detected by passive remote sensing, that takes advantage of the distinct absorption characteristics of chlorophyll $a$ in microalgae and the corresponding influence on ocean colour. Both airborne and satellite-based optical remote sensing systems have been widely applied for monitoring the magnitude and distribution of algal blooms, both benign and harmful. In $\mathrm{HAB}$ research and monitoring, remote sensing offers the possibility to track mass-surface aggregations based upon pigment spectral signatures, although not toxins or events with low cell concentration. In cases where the species identification and toxic or otherwise harmful potential has been established by independent means, such as in situ sampling or access to historical data on bloom characteristics, remote sensing is a valuable method of conducting broad scale synoptic surveys. For example, remotely sensed chlorophyll data have been used as a proxy for abundance of the Florida red-tide dinoflagellate, Karenia brevis, from which the cell abundance estimates can serve as a proxy for the brevetoxins produced during blooms (Tester et al., 2008). Further successful de- velopment of other remote sensing techniques to detect and track $K$. brevis blooms on the west Florida shelf are now being implemented (Carder and Steward, 1985; Hu et al., 2005, 2008). Recently, a novel classification approach combining high chlorophyll-low backscatter measurements allowed improved satellite detection of K. brevis (Cannizzaro et al., 2008).

We emphasize that it is not possible to discriminate toxic species or populations from non-toxic ones by large-scale remote sensing. Such methods are also not applicable for the detection of putatively toxic or harmful blooms when the organisms are present only in low biomass. It is, however, possible to identify anomalies and typical situations with high probabilities for $\mathrm{HAB}$ events that can be used as triggers to enable countermeasures for aquafarming or tourism (Stumpf, 2001; Stumpf et al., 2003; Reinart and Kutser, 2006). Aircraft observations can be automated with optical equipment, such as still- and motion-cameras, mounted on light-weight platforms such as Unmanned Aircraft Systems (Patterson and Brescia, 2008). In regions where jellyfish swarms or HABs constitute a common interference with marine enterprises and activities, such as tourism, aquaculture, navigation, etc., protocols could be developed for aerial observatory operations or satellite-based systems to detect, enumerate, and predict the development and distributional pattern of such events.

\section{Marine Pathogenic Agents (PA)}

In addition to those occurring naturally in marine waters, pathogens are carried into waterways after defecation/urination/shedding from human or animal hosts, e.g., via sewage effluent, agriculture and storm water runoff, ship waste discharges, recreational aquatic activities, industrial processes, wildlife, septic tanks near the shore, and urban development (WHO, 2001). Many pathogenic agents are of terrestrial origin, but can be carried by river discharge into marine coastal areas. The detection of pathogens via remote sensing is only possible through the detection of these source pathways. The relationship between risk of pathogens and pathways is influenced by many factors that can change rapidly, such as weather conditions, land use, redirection for agricultural or power generation purposes, and, therefore, there is a need for frequent validation through groundtruthing. The large-scale data provided by remote sensing techniques are a valuable resource, providing information on health hazards either directly or indirectly, e.g., by ocean colour or temperature gradients. Several marine hazards are not detectable from airborne or satellite-based sensors, including marine toxins, pathogens, and heavy metals and, thus, must be dealt with by in situ sensing techniques for ground-truthing and validation. 


\subsubsection{Detection on intermediate scales: in situ platforms}

Assessing processes on intermediate temporal and spatial scales, including transient events, requires even higher resolution of measurements than for large-scale remote sensing. Long time-series stations and ocean observatories need robust, reliable instruments for long duration deployments (Dickey, 2001; Daly et al., 2004), as well as an appropriate and consistent accuracy, sensitivity and selectivity that is required for use in monitoring programmes. Sensors must have sampling rates high enough to detect the development of transient events and operate over time scales at least comparable to those of physical processes (and physical sensors for conductivity, temperature, and pressure). To give an illustration: the application of an optical nutrient sensor on a winch onboard a ship produces a nearly one-dimensional data set (a depth profile) without any sample preparation on board. As part of an undulating tow-fish or a glider, the same sensor can even yield quasi two-dimensional information. The point of this example is that the dimensions of the area that can be probed depend on the capabilities of the mobile platform in combination with sensor characteristics (e.g., sampling rate). Of course the integrated sampling area will be smaller than the vast areas covered by satellites or aircraft remote-sensing, but larger than that covered by discrete shipboard water sampling from fixed depths, which often require sophisticated (non-real-time) laboratory analysis to generate results.

With respect to the recent development of mobile platforms such as floats, gliders, or AUVs, the intermediate scale is also the most relevant scale for sensor applications and development. We therefore review the portable in situ sensor technologies for the marine health hazard classes defined in the first section.

\section{Marine Pollution (MP)}

Among the laboratory devices for heavy metals, colorimetric, polarographic, and ion-selective electrode devices can most easily be made portable for field detection (Bundy et al., 1996). Polarography is an electroanalytical voltammetric method that can be adapted to perform trace level analysis with speciation capability. Several modifications of basic laboratory methodology, including changes in power supply, data acquisition, experimental control, and methods of metal extraction from test samples, are needed, however, to produce a practical, portable polarographic field sensor. Voltammetric instruments are a promising tool for in situ measurements of trace metals (Howell et al., 2003). A commercially available voltammetric in situ profiling system (VIP) (Tercier et al., 1998; Tercier-Waeber et al., 1999) has been successfully applied for autonomous, continuous monitoring in estuarine and coastal marine waters for up to one week (Tercier et al., 1998; Howell et al., 2003) with detection limits for dynamic fractions of $\mathrm{Cu}(\mathrm{II}), \mathrm{Pb}$ (II), $\mathrm{Cd}(\mathrm{II})$, and $\mathrm{Zn}$ (II) at ppb level, for $\mathrm{Mn}$ (II) at ppt level. Based on the VIP, Tercier-Waeber et al. (2005) have presented a Multi Physical-Chemical Profiler (MPCP) employing on gelintegrated voltammetric microsensors and a multi-channel voltammetric probe as well as advanced microprocessor. The MPCP includes commercially available detectors for various parameters and is constructed for the simultaneous in situ autonomous monitoring of major fractions of $\mathrm{Cu}, \mathrm{Pb}$, and $\mathrm{Cd}$, as well as $\mathrm{CTD}$, $\mathrm{pH}$, oxygen, redox $\mathrm{E}$, turbidity, and chlorophyll.

The application of a wet-chemical analyzer for determining the presence and concentration of dissolved iron(II) or manganese(II) in the water column (Prien et al., 2006) shows promise for field deployment for detecting metal pollutants. The analyzer is based on unsegmented continuous flow analysis, whereby the sample stream is inoculated with a reagent, the combined solutions are mixed and pass into a cell where the intensity of colour is determined by an LED light source and a photodiode coupled to a frequency converter as a detector. This type of in situ analyzer employs a series of valves that switches the system from pumping samples to a blank solution and a known standard. Thus, "onboard" two-point calibrations (standard and blank) can be carried out during deployment. This has the advantage that a correction for any effect that pressure and/or temperature may have on the colorimetric system can be applied to the data. The specificity for either iron or manganese is achieved through different chemical reagent regimes, but the physical instrument is the same for both analytes. Special emphasis on a fast reaction time of the analyzer (ca. $8 \mathrm{~s}$ between independent measurements) offers potential for deployment in profiling mode with concurrent CTD measurements or as payload on AUVs.

A gamma-radiation probe has been developed for radionuclide detection within a stationary monitoring network for radioactive contamination in the marine environment (German BSH, Federal Maritime and Hydrographic Agency). This detector system is based on a NaI-scintillator with a fully integrated spectrum analyzer. An interfaced processing unit measures gamma-spectra over preset observation intervals as well as integral counting of fixed gamma-energy regions. Under field conditions, this in situ method delivers comparable results to chemical analysis for nuclide mixtures originating from accidents (Wedekind et al., 1999). A specific complex energy spectra analysis of nuclides is not possible due to the relatively poor energy resolution of NaI-detectors. The KATERINA system, similar to that of the German BSH, has been developed by the Hellenic Center for Marine Research in Greece, and which incorporates a $\mathrm{NaI}(\mathrm{Tl})$ detector for the measurement of marine radiation (Tsabaris et al., 2008a and b). The system has been tested on a Remotely Operating Vehicle (ROV) (Tsabaris et al., 2008a) and integrated with fixed platforms (i.e., moorings) of the POSEIDON system. The output is configured to be transmitted via satellite to the base station (Tsabaris et al., 2008b). 
An alternative submersible program-controlled gammaspectrometer based on an HPGe detector with $38 \%$ efficiency for monitoring radionuclides by volumetric activity in water in near-real time is also available (Gostilo et al., 2000).

Petroleum hydrocarbons (included as PAHs) can be observed in situ with multispectral sensors or by detection at selected wavelengths of different optical properties of oil, among them fluorescence, reflection and absorption (see e.g., Zielinski and Brehm (2007) for a recent application and Arst (2003) for a general review). The oil groups can be classified based on fluorescence emission due to fixed wavelength excitation in the ultraviolet range, similar to the detection of oil on the water surface in airborne remote sensing (Hengstermann and Reuter, 1990). Laser induced fluorescence of oils and the effect on humic substances has also been analyzed, for example by Zimmermann et al. (1999). Nevertheless, the results of this technique can be strongly influenced by other substances in the water.

Surface-enhanced Raman scattering (SERS) is another spectroscopic method for the detection of PAHs suitable for in situ measurements. Schmidt et al. (2004) applied SERS to detect six PAH species with a flow through system at concentrations as low as a few nanograms per liter. The high specificity and fingerprinting characteristics of Raman spectra allow for substance identification in mixtures (Nguyen, 2004). The Raman measurement takes only 3-10 s and, therefore, is well suited for rapid in situ measurements. In harbour water, PAHs were found using the Multiparametric in-situ Spectroscopic Measuring Platform for Coastal Monitoring (MISPEC) including a SERS system (Kronfeldt et al., 2004). Currently, temporal and spatial resolution are limited by the adsorption kinetics of the sensor surface, with a timescale on the order of minutes (Murphy et al., 2000). This sensor is suited for stationary measurements, but improvements of the response time can be addressed with new sensor surfaces. This would make SERS a promising tool also for profiling. Other issues to resolve include the need to further decrease the limit of detection and to reduce weight and power consumption of the instruments.

An in situ ultraviolet spectrophotometer (ISUS) for the measurement of nitrate, bromide, and bisulfite, is capable of measurements at a sampling rate of $1 \mathrm{~Hz}$ (Johnson and Coletti, 2002). The same principle is applied in the in situ process photometer (ProPS), for measuring highly resolved profiles and transects from nutrient-poor to nutrient-rich waters (Zielinski et al., 2007). Both instruments are suitable for high-resolution and long-term monitoring. For nitrate measurements, Johnson et al. (2006) quote an accuracy of $\pm 2 \mu \mathrm{M}$ and a detection limit of $1.8 \mu \mathrm{M}$ for measurements at $1 \mathrm{~Hz}$ for a 2.5 year deployment. Accuracy and longterm stability of this approach can be further improved if the degrees of freedom within the algorithms are reduced by externally measured temperature and salinity information (Sakamoto et al., 2009). In comparison, the detection limits of the commercial submersible wet-chemical analyzers are about $40 \mathrm{nM}$, but the deployment times are limited by reagent consumption and degradation to less than ten weeks (Prien, 2007).

In the Spectrophotometric Elemental Analysis System (SEAS), a liquid core waveguide and long path lengths yield shipboard profiles at 0.4 to $0.75 \mathrm{~Hz}$ at nanomolar levels of nitrate and phosphate using reagent chemistry (Adornato et al., 2007). Real-time communication with SEAS will allow control of ascent/descent rates for improved measurements at specific features. The SEAS instrument can also accurately measure $\mathrm{pH}( \pm 0.0014$ units) at $0.5 \mathrm{~Hz}$ (Liu et al., 2006). In addition, simultaneous surface measurements of $\mathrm{pH}, \mathrm{CO}_{2}$ fugacity, and total dissolved inorganic carbon concentrations can be obtained with an autonomous spectrophotometric flow-through system (Wang et al., 2007).

\section{Marine Toxins (MT) and mass occurrence of toxigenic organisms}

\section{Toxin- and taxon-specific detection}

The identification of marine biotoxins, either phycotoxins or those produced by marine macrofauna (e.g., jellyfish, fish, sea snakes, cone snails), at the intermediate scale from deployable systems is (with a couple of notable exceptions) not yet realizable. One of these exceptions is the detection of the phycotoxin domoic acid produced by several species of toxigenic pennate diatoms, Pseudo-nitzschia spp., based upon a specific antibody method for the toxin (Doucette et al., 2009) and integrated into the moored Environmental Sample Processor (ESP) developed at the Monterey Bay Aquarium, Monterey, California (see detailed description in Scholin et al., 2008, 2009). The ESP system was originally designed for in situ near real-time detection of harmful algal taxa based upon their unique ribosomal DNA signatures. The molecular probes can be multiplexed for simultaneous detection of many putatively harmful species and can be hierarchically designed to reflect the closeness of target affiliations (class, order, genus, species, geographical population, etc.). Hybridization of compatible rRNA from in situ cells extracted on-line in the "sandwich hybridization assay" can be detected optically by either fluorescence or photometric sensing, which also provide a semi-quantitation of total hybridizable rRNA as a proxy for target cell number. This ESP system is now past the advanced prototype stage, and in the latest configuration has been deployed over several months on moorings in Monterey Bay, California and the Gulf of Maine, USA. Commercial production is expected to follow within the near future.

Since most marine toxins are non-volatile compounds they are not readily amenable to certain chemical analytical techniques, such as gas chromatography coupled with mass spectrometry (GC-MS), and appropriate derivatization methods for detection are not commonly available. Current applications of liquid chromatography with mass spectrometry 
(LC-MS) to marine biotoxin analysis are limited to laboratory extracted and serially injected discrete samples (Quilliam, 2003) and do not include in-water profiling or moorage deployment. The successful deployment of an advanced coupled tandem mass spectrometer (LC-MS/MS) with linear ion-trap (ABI SCIEX 4000 with Q-trap) for shipboard measurements of marine phycotoxins harvested from the water column particulate fraction in the North Sea (Krock et al., 2008) is an example of transitional analytical technology for intermediate temporal and spatial scales. In precursor ion scan mode, a wide array of putative phycotoxins belonging to different structural grouping can be assessed qualitatively and quantitatively from a single injection in $<1 \mathrm{~h}$ run time, providing quasi-synoptic spatial coverage in near-real time for these toxins while underway (Krock et al., 2009). This on board laboratory technique provided the chemical signal for the identification of the organismal source of azaspiracid toxins (Tillmann et al., 2009) - previously a mystery and major issue for shellfish toxins monitoring programs.

It would of course be significantly advantageous if LCMS systems were available for in situ applications (Marr et al., 1992) and recent developments towards miniaturization of both LC and MS technology (Taylor et al., 2001) indicate that in situ toxin analysis directly from seawater may be feasible in the not too distant future. Underwater mass spectrometers are available commercially (e.g., Applied Microsystems In-Spectr), although they are limited to analysis of very small molecules such as methane. Through the use of MEMS-based mass spectrometers (Taylor et al., 2001) the size and power demand of these systems could probably be reduced even further. On-chip or capillary LC with microfluidics would reduce the consumption of the mobile phase and the need for the vacuum pumps to remove large amounts of vapour from the interface, as well as improve sensitivity. The relatively low sample throughput (minutes to hours per sample) as well as power and space requirements of such a sensor system would likely make it best suited for larger/stationary platforms, short targeted deployments, or for ground-truthing of other sensors.

\section{Detection of high biomass HABs}

Profilers or mooring-based systems for detection of HABs are almost all based upon inherent- or apparent optical properties of the bloom and are hence generally both less sensitive and less specific than the techniques described for taxonand toxin-specific sensors. Bloom detection with the former instrumentation, therefore, typically requires high biomass (or high concentration of a proxy parameter such as chlorophyll or phycobilin-pigments), while yielding only very low taxonomic resolution (Cullen et al., 1997). Such systems also perform best when the species composition is relatively well defined and where the bloom tends to be monospecific. For the continuous detection of microalgal blooms or particle concentrations on vertical and horizontal scales, a range of commercial in situ bio-optical instruments, such as fluorometers, transmissometers, or turbidometers, are commonly available (see also the review on optical tools in this volume, Moore et al., 2008). The discrimination of valid information on microalgae or bulk material in the water is mainly solved by the relatively large amount of information obtained over temporal and spatial scales. Commercial in situ bio-optical instruments use inherent optical properties (IOPs) of substances contained in seawater, such as the specific adsorption, attenuation, scattering, and backscattering, at an increasing number of wavelengths (Babin et al., 2005). The underwater IOPs range from bulk hyperspectral to miniature multispectral instruments, and are being deployed on all types of fixed and mobile in situ platforms, e.g., buoys, ROVs, AUVs (Mitchell et al., 2000; Bishop et al., 2002; Zielinski et al., 2006b).

Fluorometers with internal light sources are used as indicators for chlorophyll concentration, a proxy for phytoplankton abundance and humic/coloured dissolved organic matter (CDOM). A second group of optical instruments employ passive sensors, which measure the distribution of light in the water column (measurement of apparent optical properties - AOPs). Values of reflectance and diffuse attenuation can be derived, e.g., from the vertical gradient in irradiance, and inversion techniques can be used to derive IOPs and water constituents (Moore et al., 2008). Passive measurements are dependent on external light sources, such as daylight and are subject to potential sources of environmental variation and uncertainty. Recently, an increasing number of hyperspectral AOP sensors are being deployed enabling sophisticated spectral fitting algorithms that can be used to derive substance concentrations in complex water bodies, e.g., in coastal areas. However, discriminating harmful from nonharmful algae species is still an open challenge for optical sensors, except if the hazard is due to relatively high algal concentrations (Kirkpatrick et al., 2000).

The most advanced development of an optical plankton discriminator (OPD, also called the "Brevebuster") has been successfully deployed to monitor and track blooms of the Florida red-tide organisms $K$. brevis (Kirkpatrick et al., 2000). Blooms of this red-tide species in Florida present a typically ideal suite of characteristics - high surface concentrations, high dominance and monospecific tendencies, plus an unusual pigment signature - that lends itself to optical detection systems. The "Brevebuster" uses a liquid capillary cell for the in vivo optical detection of the rare pigment, gyroxanthin-diester, which occurs in $K$. brevis in the eastern Gulf of Mexico and is in constant proportion to cellular chlorophyll $a$ (Millie et al., 1997). Comparing light absorption by particles in ambient water to the light absorption fingerprint characteristic of the unusual pigment signature provides a species-specific in situ detection system. The comparison yields a Similarity Index (SI) which is related to the fraction of phytoplankton community biomass contributed by K. brevis. Such OPDs are routinely deployed on 
underwater gliders to map subsurface $K$. brevis blooms on the west Florida shelf (Robbins et al., 2006). Further characterization of $K$. brevis multi-wavelength spectral properties should allow more sensitive detection with underwater spectrophotometers (Spear et al., 2009).

\section{Marine Pathogenic Agents (PA)}

As with the remote sensing of marine pathogens on a large scale, the rapid and high resolution detection of pathogens in situ is best approached by the determination of the pathways of introduction. By following the distribution of $E$. coli introduced to the marine environment from point-source measurements of inflow sources where the organisms are in high concentration, the potential pathogens can be effectively tracked on the mesoscale. An emerging development in the detection of microorganisms is the application of Raman spectroscopy (Rösch et al., 2005; Escoriza et al., 2006). Raman spectroscopy is a versatile technique to obtain fingerprints of the chemical composition of the organisms, which can then be used for identification and quantification. Field portable Raman spectrometers are commercially available from several manufacturers and there has also been some development in ocean-capable instruments, such as The Deep Ocean Raman In Situ Spectrometer (DORISS, Brewer et al., 2004).

\subsubsection{Detection on a small scale: in situ - point measure- ment}

The application of highly accurate and precise methods is necessary to quantify specific harmful substances and associated organisms and to provide unambiguous identification of the toxic components and their affiliations with particular taxa. Most conventional approaches are constrained by a time delay in delivery of results, high implementation costs, the need for highly trained personnel, and the requirement for technologically advanced equipment and laboratories. For some toxic substances, the objectives of low cost and ease of use procedures can be partially attained by access to biochemical and biomarker assays (Wells et al., 2001; Cembella et al., 2003), which can often be run in parallel for additional time saving in high-throughput screening systems. Such assays can serve for toxicity testing from a variety of sample matrices including organisms and seawater, and can be configured to be highly specific for the analytes of interest. For most environmental monitoring, structural or functional assays, frequently supplemented with chemical analytical techniques for confirmatory analysis, have largely replaced testing with whole live mammals. The one major exception for marine hazards testing is the retention of the intraperitoneal mouse bioassay (AOAC, 1990; Fernández et al., 2003) for potentially phycotoxin-contaminated seafood by many regulatory agencies around the world. In addition to the well calibrated AOAC mouse bioassay for acute toxicity, many mammalian subjects are also sacrificed for long-term toxic- ity trials of marine hazardous substances for which alternative dose-response model systems are not available. Nevertheless, increasing concerns for animal rights, as well as the confounding disadvantages of mammalian test organisms, such as effect of age, gender, acclimation history, and natural variation, and which can affect the reliability of bioassays, strongly underscore the necessity of developing alternative detection methods for marine hazardous substances.

In recent years, there has been a tremendous expansion in the use of liquid chromatography with mass spectrometry (LC-MS), especially since the advent of atmospheric pressure ionization systems (API) in the late 1980s (Quilliam, 2003). In spite of the major breakthroughs in monitoring hazardous compounds by instrumental methods (LC with fluorescence or diode-array detection; LC-MS, etc.) or in vitro assays (immunological, biomarker, biochemical, etc.) most of these approaches remain confined to the laboratory. A few advances towards near real-time techniques suitable for field deployment have been made in attempts to transduce the signal from assays via sensors, thereby facilitating the transition from single-shot probing to continuous measurements. In the following section we focus on these sensor technologies, including biosensors and electrochemical, optical, and mass-sensitive sensors.

In addition, most of the sensor technologies for small scale detection still require validation with advanced analytical equipment and laborious laboratory analysis. The new methods, therefore, can be considered as an alternative or complementary to conventional laboratory methods, such as chromatography coupled with mass spectrometry, standard culturing and microscopic examination methods, immunoassays, etc., and not necessarily as complete replacements.

\section{Marine Pollution (MP)}

Mass-produced sensors for quantitative detection of heavy metals are not generally available on a commercial scale, but test strips from several manufacturers are widely used for the semi-quantitative optical determination of a range of heavy metals. The majority of detection systems for heavy metals rely on optical and electrochemical transduction (Lieberzeit and Dickert, 2007). Optical detection of heavy-metal ions generally relies on reversible binding of the metal ions to optically active reagents, which provide both chemical selectivity and sensitivity. These can be either indicator dyes or ioncarriers which extract into a lipophilic phase on binding. The binding of heavy metal ions to these reagents is not usually specific, but rather the different ions have different affinity for the binding site. In order to provide selective quantification, arrays of different dyes or reagents can be used and the information be extracted by chemometrics. One example of electrochemical detection is stripping techniques, i.e., electrolytic accumulation followed by dissolution, and detection of the latter process. The response to a range of heavy metals instead of a specific one is described as one disadvantage of a 
biosensor by Liao et al. (2006), although this may be required for a range of objectives. Oehme and Wolfbeis (1997) recommend that a combination of spectroscopic methods, such as multi-wavelength spectrometry and measurement of decay time with chemometrics, is a good approach to quantify more than one analyte.

A prototype sensor for radionuclides has been described by Tarancón et al. (2005). Low-level active solutions of ${ }^{90} \mathrm{Sr} / 90 \mathrm{Y},{ }^{238} \mathrm{Pu},{ }^{134} \mathrm{Cs}$ and ${ }^{60} \mathrm{Co}$ can be detected. This sensor has errors of $<10 \%$ with a sensor based on a plastic scintillator receptor capable of continuous, on-time and accurate remote quantification of the activity of $\alpha, \beta$ and $\beta-\gamma$ emitters. Grate et al. (2008) describe a minicolumn sensor for the detection of radionuclides with a sensing approach based on equilibrium in the columns.

Many toxic organic compounds can either be detected by enzymatic inhibition assays or via antibodies in immunosensors (Suri et al., 2002). A wide range of biosensors exists for the detection of pesticides (Solé et al., 2003), some of which can be classified as immunosensors. The amperometric biosensor Cellsense with E. coli (Farré et al., 2001) detects potentially toxic compounds, such as phenol derivatives, non-ionic surfactants and benzene sulfonate compounds, by measuring the electrical current produced by the bacteria's electron transport chain in wastewaters. One method for the detection of organotin compounds (TBT and DBT) is also based on a bacterial bioassay (Durand et al., 2003). Biosensors are also commercially available for the detection of nutrients, as described for nitrate and nitrite by Larsen et al. (1997) and for phosphate by Engbloom (1998).

Another relevant health hazard that is addressed by smallscale measurements are hormones and their metabolites, which can negatively affect endocrine systems, especially those of aquatic organisms. Endocrine-disrupting compounds may be natural or synthetic chemicals, such as pesticides, plasticizers, pharmaceuticals, cosmetics, household products and industrial chemicals, which interfere with hormonal systems or mimic hormones and block their function. The presence of these "hormone analogues" at only trace levels and their high similarly to naturally synthesized hormones produced by the organisms complicates the detection and measurement. Sensor development is in an early stage, but includes both biomimetic recognition systems and DNA microarrays (Sesay and Cullen, 2001; Asano et al., 2004; Tschmelak et al., 2005).

\section{Marine Toxins (MT) and mass occurrence of toxigenic or- ganisms}

As outlined before, the detection of many marine toxins via whole mouse assays, e.g., the AOAC intraperitoneal mouse bioassay for PSP toxins, remains a method in widespread use and is internationally accredited. For example, the mouse bioassay is still an EU reference method for detection of certain phycotoxins in shellfish (Aune et al., 2007). For replace- ment in the current EU legislation, alternative methods need to be validated according to an internationally recognised protocol. Such methodologies focus by now on laboratory methods, such as LC-MS (Alexander et al., 2008).

Several alternative in vitro assays, including in receptor binding assays, biochemical assays, immunoassays and electrochemical immunosensors have been developed and are increasingly applied in seafood toxin monitoring programmes (Cembella et al., 2003; Fernandez et al., 2003). Chemical analytical methods such as chromatographic or electrophoretic techniques and mass spectrometry are now widely employed for the detection of marine toxins (Quilliam, 2003). The large variety of functional and structural assays for phycotoxin monitoring are unfortunately mainly targeted to a specific toxin or selected group of toxins and, therefore, do not provide a broad spectrum screening (Rossini, 2005). Furthermore, interference by nonspecific matrix effects or limited availability of standard reference materials may also impair the application of these techniques for general routine measurement (Campbell et al., 2007).

There is no ideal method for toxin determination and, therefore, methods that reliably detect toxic substances in a rapid, low-cost and easy-to-use way are still required. Rapid developments are occurring in the leap from whole animal and tissue culture assays to biosensors, and from simple immunoassays (e.g., colorimetric or fluorometric ELISA) to sophisticated immunosensors (Campás et al., 2007). Biosensors also have potential as a partial alternative and/or complementary tool to long established technologies. For example, Campás et al. (2007) developed an amperometric immunosensor assay which was compared with the protein phosphatase inhibition (PPI) assay and conventional HPLC analysis of cyanotoxins. The immunosensor proved its applicability as a screening tool for fast and reliable cyanotoxin detection. Given the success in detecting low level chemical contaminants in food, optical biosensors based on surface plasmon resonance technology also have the potential to be an alternative strategy for monitoring PSP toxins in seafood (Campbell et al., 2007).

\section{Detection of high biomass HABs}

The detection of HABs on the toxin- or species level is crucial for HAB monitoring, as the harmful effects are often attributable to single or at least dominant species. In particular, sensors are needed to detect HABs at low background concentrations to allow early warning of bloom development and possible mitigation strategies. Traditional observation techniques for algal species on a small spatial scale include light microscopy and laboratory analysis, which are labourintensive methods that do not deliver real-time results or broad coverage (LaGier et al., 2007). Emerging techniques for near real-time monitoring of phytoplankton include the benchtop FlowCAM®, combining microscopy and flow cytometry in measuring light-scattering and fluorescence from 
chlorophyll and phycoerythrin on individual particles larger than $5 \mu \mathrm{m}$ coupled with image capture capabilities allowing for the recognition of species (Sieracki et al., 1998). The FlowCytobot is an automated submersible flow cytometer that has been used to analyze pico- and nanoplankton (Olson et al., 2003). Techniques depending on single cell analysis, however, may be inappropriate for the colonies or coiled filaments of cyanobacteria (Codd et al., 2005). Another autonomous in situ flow cytometer, the CytoBuoy, has been employed to quantify marine plankton, including the difficult HAB organism Phaeocystis spp., which tends to form amorphous gelatinous colonies (Rutten et al., 2005). The CytoBuoy allows phytoplankton analysis in the size range 1- $50 \mu \mathrm{m}$ (for more details see e.g. Thyssen et al., 2008).

Molecular techniques have already been developed for in situ detection of HAB organisms even at low biomass concentrations. One deployable molecular-based detection system, the moored Environmental Sample Processor (ESP) uses a rRNA hybridization approach (see 3.1.2 MT, Scholin et al., 2008). An alternative system, the Autonomous Microbial Genosensor (AMG) (Paul et al., 2007) can also collect and process plankton samples in the ocean. The AMG operates by nucleic acid sequence-based amplification, with an initial configuration designed to detect $K$. brevis. This instrument is designed to be deployed on moorings and transmit data to shore in near real-time. Development of "phylochips" and DNA microarrays for selected taxa including harmful algal species are underway (Metfies and Medlin, 2008) but are not yet configured for in situ deployment.

\section{Marine Pathogenic Agents (PA)}

There is no universal method for the routine detection of all pathogenic agents of interest in a given water sample. This is due to the physical differences between the major pathogen groups, the presence of co-concentrated inhibitors in the sample and the requirement for standardizing a cultureindependent endpoint detection method (Straub and Chandler, 2003). Such a universal method may be eventually based on recent advances in sample collection, on-line sample processing and purification and DNA microarray technologies.

Faecal indicator bacteria (e.g., faecal/thermotolerant coliforms, E. coli, enterococci/faecal streptococci) are used as indicators because it is not possible to routinely measure all marine pathogens. For marine waters, the WHO (2001a) recommends faecal streptococci as an indicator for recreational use of marine waters, as these show a dose-response relationship for both gastrointestinal illness (Kay et al., 1994) and AFRI (Fleisher et al., 1996b). One technique towards the detection and enumeration of waterborne pathogens comprises flow cytometry with autofluorescence/immunofluorescence (Parthuisot et al., 2000). A rapid biodetector in the form of a small surface plasmon resonance sensor (Spreeta ${ }^{\circledR}$ SPR) (Spangler et al., 2001) has been employed for detection of
E. coli enterotoxin in minutes within the detection range from $70 \mathrm{~nm}(6 \mu \mathrm{g} / \mathrm{ml})$ to $600 \mathrm{~nm}(50 \mu \mathrm{g} / \mathrm{ml})$ toxin protein (MW $85000 \mathrm{Da})$.

\subsection{Coverage and gaps}

Review of the state-of-technology reveals well established and proven, as well as not yet mature sensing approaches for marine health hazards on different spatial and temporal scales. Efforts to detect, monitor, track, and predict harmful substances and organisms by remote sensing techniques, in situ measurements with sensors and sensor systems, as well as fine-scale laboratory analysis, reveals that each methodology has advantages as well as limits to its range of implementation.

Remote sensing on a large scale is not a complete solution, but is useful for synoptically monitoring harmful substances or proxies. At the other end of the spectrum, dedicated laboratory measurements provide accurate and extensive measurements of a single water sample, but owing to the labour and time-intensive methods, they cannot yield higher spatial or temporal resolution within affordable budgets and resources. A combination of these applications, specifically an integration of large-scale quasi-synoptic data with high resolution surveys and laboratory in-depth analysis, can partly overcome the constraints of a single approach. This combination of scales will provide additional insight and decision making information. A gap remains for new sensing technologies, especially on the intermediate scale, where remote sensing and laboratory measurement intersect. The application of in situ sensors and sensor systems on moorings, ships of opportunity, and so on hold the possibility of combining some advantages of precise laboratory methods and remote sensing to address the demand for high resolution long-term data sets with broad spatial coverage.

Many sensors described herein still require research and development. Especially for detection of heavy metals, POPs, and pathogenic agents full commercialization has often not been achieved, whereas other devices (e.g., for detection of chlorophyll and nitrate) are already available often from multiple manufacturers (Table 1).

\section{Future demands and upcoming technologies}

Some of the categories of health hazards are already addressed by a variety of commercialized sensor techniques. Whereas the areas where few sensors are available might be interpreted as an indication of critical immediate future needs, not all approaches are technically feasible or even recommended for the end-user community. For example, the demand for species identification via remote sensing from satellites or aircraft is simply not feasible as the required specifications typically exceed the laws of physics. In many cases, the analysis of marine hazard parameters has been 
Table 1. Compilation of commercially available in situ sensors for long-term applications in marine environments.

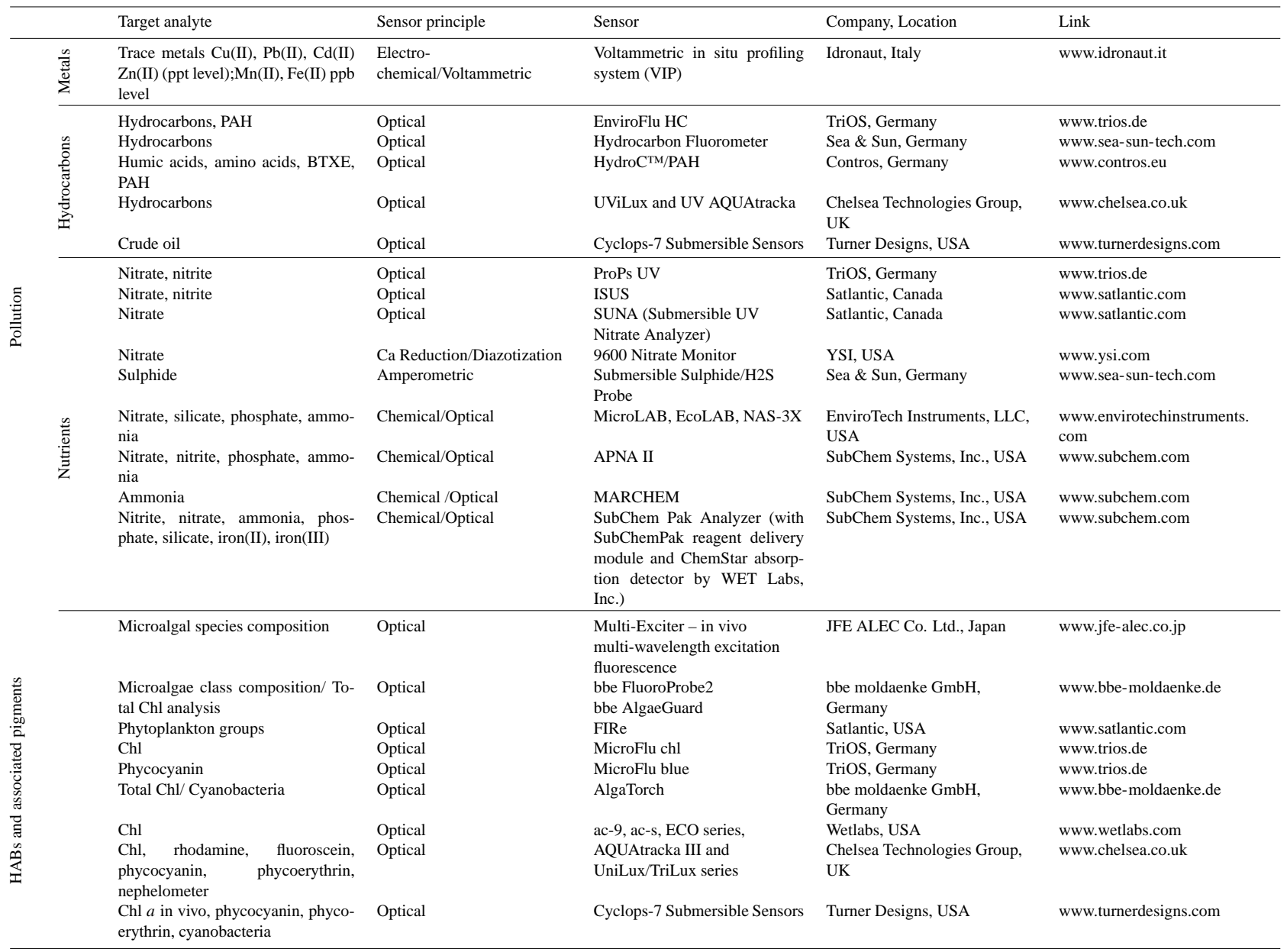

approached by measuring what is easy (e.g., chlorophyll by fluorosensors or particle spectra and fluorescence of picoplankton by flow cytometry) merely because the technology is available, but not because the results are always relevant. Hope is, however, justified in the proposed adoption of the underlying principles of laboratory analytical measurements to be applied to the field. With respect to in situ technologies, there are grounds for optimism that many demands will eventually be satisfied, in spite of the technical and financial constraints in transferring laboratory prototypes to deployable sensor systems. The need for detection of certain substances may not yet be strong enough on all scales to catalyze the required efforts for technical development. Furthermore, the replacement of statutory laboratory methodologies by sensor technology is only possible if comparable (or better) sensitivity and selectivity towards the target analyte is accomplished and can be proven. Proof may take the form of various quality assurance procedures, which include visual inspection and performance monitoring of the sensor, pre- and post-deployment calibra- tion, and inter-comparison of measurements with established analytical methodologies (Waldmann et al., 2009). Combining technology gaps with social demands will drive the needs and priorities for future development. For the monitoring programmes robust and reliable instruments for long duration deployment are needed. Here, development should focus on consistent accuracy, sensitivity, and selectivity of the sensors during deployment. The effect of fouling on the quality of data is an issue and sensor performance needs to be underpinned by quality assurance data using reference methods. For this purpose deployment of autosamplers alongside sensors could enable collection of reference samples.

Within the broad field of aquatic pollution, there is a large demand for sensors from the oil and gas industry. Petroleum hydrocarbons, such as oil or PAHs on the water surface in dissolved form, are already addressed by a couple of commercial optical sensors on all scales. This underlines the high ecological and economic relevance of the observed processes and parameters. There is, however, a need for further improvements in detection, classification, and quantification of 
petroleum hydrocarbons, e.g., for the determination of leakages in pipelines or for the concentration in bilge water. Detection is required to be fast, reliable, and affordable to support monitoring- and alarm functions. UV-LED light sources and multispectral excitation-emission configurations are just two examples for the ongoing progress in these sensor technologies. Classification and quantification techniques for in situ application that have been available before only in a laboratory environment and at high costs include the combination of hyperspectral and time-resolved fluorescence sensors (Rohde et al., 2009), surface enhanced Raman spectroscopy, liquid waveguide capillary cells, and attenuated total reflection (ATR) spectroscopy using the evanescent field in coated fibres. The latter is especially suited for measurements in the presence of high amounts of suspended material (at river mouths, etc.) or high background absorbance.

The accumulation of heavy metals and persistent organic pollutants in the sediment involves a danger for the benthic ecosystem and the risk of releasing toxic substances over time, e.g., pollutants can return to the food chain upon resuspension due to storms or floods. Algal toxins and the causative organisms may be present in the water or accumulated in the food web after a bloom condition. Therefore, the detection of hazardous substances and organisms some time after an environmental stressor needs to be taken into account by coastal management and surveillance measures in the future.

For the assessment of the chemical status of marine ecosystems, as is for example required for the EU WFD, a variety of parameters need to be tracked over large temporaland spatial scales in a rather precise resolution. Substances include chemical polluting elements as well as physicochemical elements, such as nutrients. The WFD also requires the assessment of ecological status. Phytoplankton are included within the biological elements considered in the WFD. Established indicators in this respect are phytoplankton biomass, taxonomic composition and abundance, as well as the frequency of blooms (OJEC, 2000). The accurate and timely identification of harmful algal species and measurement of their toxins is fundamentally important to both HAB research and management. Mitigation could also be facilitated by early detection of toxic blooms. Cell counts of putatively toxic microalgae are often used as a proxy for inferring the presence of phycotoxins (Steidinger et al., 1999; Kirkpatrick et al., 2000), but these quantitative estimates are not very reliable because of large differences in cell toxin content among members of the same morphospecies and the ephemeral nature of the associated blooms.

A Florida State task force (Steidinger et al., 1999) identified six priority areas of study regarding HABs and their toxins, but this list is also reflective of global requirements: 1) determine the distribution of toxic and non-toxic strains, 2) develop epidemiological studies to determine public health risks, 3) develop economic impact studies to evaluate losses by location or industry, 4) determine the roles of nutrient en- richment and managed freshwater flow in blooms, 5) determine fate and effects of toxins in the food web, and 6) investigate control and mitigation methods, including hand-held and autonomous biosensors. The development and application of sensor methodologies would support the Member States of the EU in the WFD objective to reach a good surface water status by the year 2015 .

Biosensors are a clear priority for detection of harmful algae and their respective toxins. Approaches such as membrane-ion channel biosensors, surface plasmon resonance-based biosensors (see Campbell, 2007), and molecular and biochemical diagnostic procedures (e.g., immunoassays) must be further advanced to comply with the sensitivity requirements to replace the AOAC mouse bioassay.

For marine biotoxins, a single procedure covering multiple classes of toxins would provide the best standard for consumer protection (Rossini, 2005). Unfortunately such a method does not exist - the application of LC-MS/MS to toxin analysis comes closest, but has the major drawback of not directly measuring toxicity and cannot effectively screen for new classes of toxins without prior knowledge of chemical structure and evidence of toxicity. There remains a residual requirement for development of functional assays to determine toxin potency to at least partially replace whole animal bioassays. The range of biosensors for seafood toxicity screening allows detection of phycotoxins at adequate sensitivities, but their limited availability, primarily as research tools, hinders their broader utilization in monitoring programmes. Commercial exploitation could be enhanced by combining existing knowledge in interdisciplinary areas, such as nanoelectronics, bioelectronics, micromachining, and microfluidics (Campas et al., 2007). This would also contribute to the implementation of these devices on deployable measurement platforms.

Pathogen detection constitutes the least developed field of sensor development within the framework of this review. To fulfil the demands of the Bathing Waters Directive 2006/7/EC, continuous sensor devices to monitor the presence of fecal indicators and waterborne pathogens would form a clear advantage. Biosensors may form a solution for this demand.

A largely overlooked hazard for marine ecosystems has been synthetic micro- and nanoparticles. Microparticles $(<20 \mu \mathrm{m}$ in diameter) are largely the by-product of fragmentation of larger plastic debris (Thompson et al., 2004). These particles are ingested by a variety of marine animals, and they have been shown to readily adsorb phenanthrene, a priority pollutant (Teuten et al., 2007). Nanoparticles $(<0.1 \mu \mathrm{m}$ in diameter) may be generated by further fragmentation of microparticles, but they may also be industrially mass-produced. The presence of nanoparticles in seawater may entail medical and environmental hazards, due to their ability to pass through cell membranes without cell wall disruption (Verma et al., 2008). The effects on the food web, 
human health, and the marine environment at large remain to be shown, but it is important to be aware of this issue. Further awareness will assist in foreseeing the capability to detect and enumerate synthetic micro- and nanoparticles in coastal areas where sources of hazardous pollutants such as PCBs are present and coincide with commercially important species, such as suspension-feeders (e.g. mussels).

The development of ecogenomic sensors is a future domain of investigation. Within this field, besides the definition of target compounds, methods for detection and signal transduction need to be established (see Scholin, 2009). In addition to biosensor and ecogenomic sensor-based applications, Raman and imaging-based techniques are promising tools to reach a higher sensitivity towards the target analytes and organisms. Although there has been some success in the application of Raman spectroscopy in the detection of health hazards (Brewer et al., 2002; Kronfeldt et al., 2004), this technique may be also regarded as an emerging technique for field deployment, due to the high potential for measuring inorganic and organic compounds even under extreme conditions (e.g., detection of leaking dumped ammunition or non-fluorescent CHCs is conceivable). In addition to conventional Raman scattering, sophisticated techniques such as SERS or resonance Raman can be employed to increase the sensitivity for specific compounds in a complex mixture, e.g., carotenoids and chlorophyll pigments in algae.

A different approach towards the aim of detecting hazardous organisms is the use of image forming devices. Systematic efforts in underwater imaging have been carried out since the 1970s (see Wiebe and Benfield, 2003, and references therein). Current digital technology allows sensing of object size classes below $100 \mu \mathrm{m}$ and on spatial scales in the decimetre range. However, the required high magnification results in small volumes scanned per frame. Thus, particles with low abundances have a higher probability to remaining undetected until their number increases (Davis et al., 1992; Benfield et al., 1996). Another imaging system, the SIPPER, utilizes a high-speed linescan camera to continuously image all particles passing through a relatively larger volume of water (Remsen et al., 2004) and an image analysis software to measure and identify plankton (Luo et al., 2004). Recent research also is being conducted towards automatic species identification based on research platforms, such as the Lightframe On-sight Keyspecies Investigation method (LOKI) (Schulz et al., 2008). The LOKI acquires images of objects in a defined volume and assigns them to environmental parameters. The challenge is to ensure the reliability of the post-processing with autonomous and correct identification of particles. In addition to standard parameters, like Hu-moments, Fourier-descriptors or texture analysis, the classification algorithms includes new form based feature extractions (Latecki and Lakämper, 2000, ISO/IEC TR 159388, 2002), increasing classification success.

Considering the increased computational and network capacities onboard modern in situ observation platforms, it is possible to realize their autonomous, adaptive response. For example, modeling can be applied to help cast projections of biological, chemical and physical properties. By directing small fleets of mobile platforms or altering the operation of a fixed array of sensors and samplers within that domain, a distributed network could be variably tuned to remotely detect specific phenomena.

Further progress in sensor technology is expected to depend largely on the development of small-scale laboratory sensor technologies with a high sensitivity and specificity towards the target analyte or organism. Deployable systems, however, must comply with platform requirements, as the latter connect the small- to the large scale. In any case, the combination of sensor techniques applicable to all scales will remain crucial for the coverage of all spatial and temporal dimensions.

\section{Conclusions and outlook}

In the past several decades, a large variety of measurement devices and sensing systems have been designed. This interdisciplinary field is characterized by a rapid technical development in disciplines such as science, systems engineering and field operation systems. We used the reciprocal relationship between the area coverage and the information depth obtained by the available sensors for these different spatial dimensions to organise our review. From this status quo, a large window of opportunity is evident for the advancement of sensors in marine hazard detection on all scales. Ancillary requirements for monitoring and operational oceanography are improvements in the SWaP-factor (size, weight, and power consumption), biofouling prevention, handling, reagent free operation, real-time data availability, as well as simplified deployment and maintenance. Additional issues of stability and reliability and the testing of techniques, e.g., in ring trials to reach comparable results of multiple users, must also be addressed. Current ocean-observation efforts are limited in scope and as yet do not have clear mechanisms for translating large-scale, international ocean experiments into long-term, operational observation efforts, or for transitioning emerging new ocean-observation technologies to operational use (NOAA, 2008c). This is particularly true with respect to monitoring of (non-physical) marine hazards. The focus here should be on the operational oceanography aspects of in situ sensors with more precise measurements and integration with data via space- and airborne systems, especially on the intermediate scale.

The future of ecological risk assessment will, according to Hope (2006), focus increasingly on larger spatial scales and the need for scientific, defendable, and implementable assessment tools beyond single organisms to large ecosystems. This will require a continued application and development of sensors to cover (spatially and temporally) an assessment of 
multiple stressors, including meta-data storage and analysis capacities.

Furthermore, improved communication amongst all decision makers, stakeholders, and lay audiences is required. This is beyond the scope of a sensor review paper. It is, however, important for the creation of data protocols, analysis tools, and for clear, effective management strategies and for the consideration of the socioeconomic consequences of marine hazards. The protection and restoration of habitats via improved detection and monitoring of hazardous substances, organisms, and linkages with associated critical processes, through sensors and sensor systems will contribute to the prevention and mitigation of adverse effects.

Acknowledgements. This work is based on the session "Health Hazards from the Ocean" of the OceanSensors08 workshop held 31 March-4 April 2008 in Warnemünde, Germany. The authors thank all participants of this workshop and the reviewers of the OSD manuscript for their valuable discussion input and comments. We also acknowledge the work of T. Dickey, R. Prien, and G. Griffiths for their effort to concentrate and collect knowledge on the status quo of sensor techniques and development in this workshop and to make this information available to the public by means of this special edition in Ocean Science.

Edited by: R. Prien

\section{References}

Adornato, L. R., Kaltenbacher, E. A., Greenhow, D. R., and Byrne, R. H.: High-resolution in situ analysis of nitrate and phosphate in the oligotrophic ocean, Environ. Sci. Technol., 41, 4045-4052, 2007.

Alexander, J., Auðunsson, G. A., Benford, D., Cockburn, A., Cravedi, J.-P., Dogliotti, E., Di Domenico, A., Fernández-Cruz, M. L., Fink-Gremmels, J., Fürst, P., Galli, C., Grandjean, P., Gzyl, J., Heinemeyer, G., Johansson, N., Mutti, A., Schlatter, J., van Leeuwen, R., Van Peteghem, C., and Verger, P.: Opinion of the Scientific Panel on Contaminants in the Food chain on a request from the European Commission on marine biotoxins in shellfish - okadaic acid and analogues, The EFSA Journal, 589, $1-62,2008$.

Anderson, D. M., Glibert, P. M., and Burkholder, J. M.: Harmful algal blooms and eutrophication: nutrient sources, composition, and consequences, Estuaries, 25, 704-726, 2002.

Anderson, D. M., Townsend, D. W., McGillicuddy Jr., D. J., and Turner, J. T.: The ecology and oceanography of toxic Alexandrium fundyense blooms in the Gulf of Maine, Deep Sea Res. II, 52 19-21), 2365-2876, 2005.

Arst, H.: Optical properties and remote sensing of multicomponental water bodies, Springer, 231, 2003.

Asano, K., Ono, A., Hashimoto, S., Inoue, T., and Kanno, J.: Screening of endocrine disrupting chemicals using a surface plasmon resonance sensor, Anal. Sci. 20(4), 611-616, 2004.

Aune, T., Larsen, S., Aasen, J. A. B., Rehmann, N., Satake, M., and Hess, P.: Relative toxicity of dinophysistoxin-2 (DTX-2) compared with okadaic acid, based on acute intraperitoneal toxicity in mice, Toxicon, 49, 1-7, 2007.
Babin, M., Cullen, J. J., Roesler, C. S., Donaghay, P. L., Doucette, G. J., Kahru, M., Lewis, M. R., Scholin, C. A., Sieracki, M. E., and Sosik, H. M.: New approaches and technologies for observing harmful algal blooms, Oceanography, 18(2), 210-227, 2005.

Babin, M., Roesler, C. S., and Cullen, J. J. (Eds.): Real-time coastal observing systems for marine ecosystem dynamics and harmful algal blooms, UNESCO publishing, Paris, 807 pp., 2008.

Benfield, M. C., Davis, C. S., Wiebe, P. H., Gallager, S. M., Lough, R. G., and Copley, N. J.: Video plankton recorder estimates of copepod, pteropod and larvacean distributions from a stratified region of Georges bank with comparative measurements from a MOCNESS sampler, Deep-Sea Res. II, 43, 1925-1946, 1996.

Bishop, J., Davis, R. E. and Sherman, J. T.: Robotic observations of storm dust enhancement of carbon biomass in the North Pacific, Science, 298, 817-821, 2002.

Bonn Agreement: Aerial Surveillance Handbook Part 2, Remote Sensing and Operational Guidelines, Version: 25 October 2007, 33, 2007.

Bundy, K. J., Berzins, D., and Taverna, P.: Development of polarographic sensors for heavy metal detection sensing applications. Proceedings of the HSRC/WERC Joint Conference on the Environment, Great Plains/Rocky Mountain Hazardous Substance Research Center, 1996.

Brewer, P. G., Malby, G., Pasteris, J. D., White, S. N., Peltzer, E. T., Wopenka, B., Freeman, J., and Brown, M. O.: Development of a laser Raman spectrophotometer for deep-ocean science, DeepSea Res. I, 51, 739-753, 2004.

Browell, E. V.: Analysis of laser fluorosensor systems for remote algae detection and quantification, NASA Technical Note, TN D-8447, 1977.

Cabelli, V. J., Dufour, A. P., McCabe, L. J., and Levin, M. A.: Swimming associated gastroenteritis and water quality, Am. J. Epidemiol., 115, 606-616, 1982.

Campbell, K., Stewart, L. D., Doucette, G. J., Fodey, T. L., Haughey, S. A., Vilarino, N., Kawatsu, K., and Elliott, C. T.: Assessment of specific binding proteins suitable for the detection of paralytic shellfish poisons using optical biosensor technology, Anal. Chem., 79, 5906-5914, 2007.

Campás, M., Prieto-Simón, B., and Marty, J.-L.: Biosensors to detect marine toxins: Assessing seafood safety, Talanta, 72(3), 884-895, 2007.

Cannizzaro, J. P., Carder, K. L., Chen, F. R., Vargo, G. A., and Heil, C. A.: A novel technique for detection of the toxic dinoflagellate, Karenia brevis, in the Gulf of Mexico from remotely sensed ocean color data, Cont. Shelf Res., 28, 137-158, 2008.

Carder, K. L. and Steward, R. G.: A remote-sensing reflectance model of a red-tide dinoflagellate off west Florida, Limnol. Oceanogr., 30, 286-298, 1985.

Cembella, A. D., Doucette, G. J., and Garthwaite, I.: In vitro assays for phycotoxins, in: Manual on Harmful Marine Microalgae, edited by: Hallegraeff, G. M., Anderson, D. M., and Cembella, A. D., Monographs on Oceanographic Methodology, 11, 297-345, UNESCO, Paris, 2003.

Cheung, W. H., Chang, K. C., Hung, R. P., and Kleevens, J. W.: Health effects of beach-water pollution in Hong Kong, Epidemiol. Infect., 105, 139-162, 1990.

Christiansen, L. B., Winther-Nielsen, M., and Helwig, C: Feminisation of fish. The effect of estrogenic compounds and their fate in sewage treatment plants and nature, Environmental Project No. 
729; Danish Environmental Protection Agency, online available at: http://www.mst.dk/udgiv/publications/2002/87-7972-305-5/ html/default_eng.htm, 2002.

Codd, G. A., Morrison, L. F., and Metcalf, J. S.: Cyanobacterial toxins: risk management for health protection, Toxicol. Appl. Pharmacol., 203, 264-272, 2005.

Corbett, S. J., Rubin, G. L., Curry, G. K., and Kleinbaum, D. G.: The health effects of swimming at Sydney beaches, Am. J. Public Health, 83, 1701-1706, 1993.

Cullen, J. J., Ciotti, A. M. Davis, R. F., and Lewis, M. R.: Optical detection and assessment of algal blooms, Limnol. Oceanogr., 42, 1223-1239, 1997.

Daly, K. L., Byrne, R. H., Dickson, A. G., Gallager, S. M., Perry, M. J., and Tivey, M. K.: Chemical and biological sensors for timeseries research: current status and new directions, Mar. Technol. Soc. J., 38(2), 121-143, 2004.

Davis, C. S., Gallager, S. M., and Solow, A. R.: Microaggregations of oceanic plankton observed by towed video microscopy, Science, 257, 230-232, 1992.

Dickey, T. D.: The role of new technology in advancing ocean biogeochemical research, Oceanography, 14(4), 108-120, 2001.

Directive 2000/60/EC of the European Parliament and of the Council of 23 October 2000 Establishing a Framework for Community Action in the Field of Water Policy, 2000.

Directive 2006/7/EC EC of the European Parliament and of the Council of 15 February 2006 concerning the management of bathing water quality and repealing Directive 76/160/EEC, 2006.

Directive 2008/56/EC of the European Parliament and of the Council of 17 June 2008, establishing a framework for community action in the field of marine environmental policy, 2008.

Doucette, G. J., Mikulski, C. M., Jones, K. L., King, K. L., Greenfield, R., Marin III, R., Jensen, S., Roman, B., Elliot, C. T., and Scholin, C. A.: Remote, subsurface detection of the algal toxin domoic acid onboard the Environmental Sample Processor: assay development and initial field trials, Harmful Algae, in press, 2009.

Durand, M. J., Thouand, G., Dancheva-Ivanova, T., Vachon, P., and DuBow, M.: Specific detection of organotin compounds with a recombinant luminescent bacteria, Chemosphere, 52, 103-111, 2003.

Endo, S., Takizawa, R., Okuda, K., Takada, H., Chiba, K., Kanehiro, H., Ogi, H., Yamashita, R., and Date, T.: Concentration of polychlorinated biphenyls (PCBs) in beached resin pellets: variability among individual particles and regional differences, Mar. Poll. Bull., 50, 1103-1114, 2005.

Engblom, S. O.: The phosphate sensor, Biosens. Bioelectron., 13, 981-994, 1998.

Farré, M., Pasini, O., Alonso, M. C., Castillo, and M., Barceló, D.: Toxicity assessment of organic pollution in wastewaters using a bacterial biosensor, Anal. Chim. Acta, 426, 155-165, 2001.

Escoriza, M. F., VanBriesen, J. M., Stewart, S., Maier, J., and Treado, P. J.: Raman spectroscopy and chemical imaging for quantification of filtered waterborne bacteria, J. Microbiol. Meth., 66(1), 63-72, 2006.

FAO: AQUALEX, Multilingual glossary of aquaculture terms, online available at: www.fao.org/fi/glossary/aquaculture/default. asp, 2008.

Fernández, M. L., Richard, D. J., and Cembella, A. D.: In vivo bioassays for phycotoxins, in: Manual on Harmful Marine Mi- croalgae, edited gby: Hallegraeff, G. M., Anderson, D. M., and Cembella, A. D., Monographs on Oceanographic Methodology, 11, 347-380, UNESCO, Paris, 2003.

Fleisher, J. M., Kay, D., Wyer, M. D., and Godfree, A. F.: Marine Waters contaminated with domestic sewage: nonenteric illnesses associated with bather exposure in the United Kingdom, Am. J. Pub. Health, 86(9), 1228-1234, 1996a.

Fleisher, J. M., Kay, D., Wyer, M. D., and Merrett, H.: The enterovirus test in the assessment of recreational water-associated gastroenteritis, Water Res., 30, 2341-2346, 1996b

Gade, M.: On the imaging of biogenic and anthropogenic surface films on the sea by radar sensors, in: Marine Surface Films: Chemical Characteristics, Influence on Air-Sea Interactions, and Remote Sensing, edited by: Gade, M., Hühnerfuss, H., and Korenowski G. M., 189-204, 342 pp., Springer, Heidelberg, 2006.

Geisterdoerfer, P. and Goyffon, M.: Animaux aquatiques dangereux. EMC, Toxicologie-Pathologie, 1(2), 35-62, 2004.

GEOHAB: Global Ecology and Oceanography of Harmful Algal Blooms, online available at: http://www.geohab.info/, 2008.

GESAMP: Report of the Thirteenth Session, Geneva, Switzerland, 28 February-4 March 1983, IMO/FAO/UNESCO/WMO/WHO/IAEA/UN/UNEP Joint Group, of Experts on Scientific Aspects of Marine Pollution, Reports and Studies, 18, WMO, Geneva, Switzerland, 50 pp., 1983.

GESAMP - IMO/FAO/UNESCO/WMO/WHO/IAEA/UN/UNEP Joint Group, of Experts on Scientific Aspects of Marine Pollution, Review of Potentially Harmful Substances, Nutrients, Reports and Studies, UNESCO-IOC, Paris, France, 34, 40 pp., 1990.

Gerba, C. P.: Pathogens in the environment, in: Pollution Science, edited by: Pepper, I. L., Gerba, C. P., and Brusseau, M. L., Academic Press, New York, 279-299, 1996.

GOOS: Global Ocean Observing System, online available at: www. ioc-goos.org, 2008.

Gostilo, V., Sokolov, A., Danengirsh, S., Kondrashov, V., Loupilov, A., Fedotenkov, V., Pchelintsev, A., Nekrestjanov, S. N., Kireyev, V. F., Pichteyev, O. Y., Ivanov, V. P., and Likov, D. V.: Floating monitoring station for measurements of radionuclides volumetric activity in water reservoirs, Nuclear Science Symposium Conference Record, IEE, 2000.

Graham, E. R. and Thompson, J. T.: Deposit- and suspensionfeeding sea cucumbers (Echinodermata) ingest plastic fragments, J. Exp. Mar. Biol. Ecol., 368(1), 22-29, 2009.

Graham, W. M., Pagès, F., and Hamner, W. M.: A physical context for gelatinous zooplankton aggregations: a review, Hydrobiologia, 451(1-3), 199-212, 2001.

Grate, J. W., Egorov, O. B., O’Hara, M. J., and DeVol, T. A.: Radinuclide Sensors for Environmental Monitoring: From Flow Injection Solid-Phase Absorptiometry to Equilibration-Based Preconcentrating Minicolumn Sensors with Radiometric Detection. Chemical Reviews ASAP Articles, online available at: http: //pubs.acs.org/doi/pdf/10.1021/cr068115u, 2008.

Grovel, O., Pouchus, Y. F., and Verbist, J.-F.: Accumulation of gliotoxin, a cytotoxic mycotoxin from Aspergillus fumigatus, in blue mussel (Mytilus edulis), Toxicon, 42, 297-300, 2003.

Grüner, K., Reuter, R., and Smid, H.: A new sensor system for airborne measurements of maritime pollution and of hydrographic parameters, GeoJournal, 24(1), 103-117, 1991. 
HELCOM: Hazardous substances of specific concern to the Baltic Sea - Final report of the HAZARDOUS project, Baltic Sea Environment Proceedings, 119, 96 pp., 2009.

Hengstermann, T. and Reuter, R.: Lidar fluorosensing of mineral oil spills on the sea surface, Appl. Optics, 29(22), 3218-3227, 1990.

Hoge, F. E. and Swift, R. N.: Airborne dual laser excitation and mapping of phytoplankton photopigments in a gulf stream warm core ring, Appl. Optics, 22(15), 2272-2281, 1983.

Hope, B. K.: An examination of ecological risk assessment and management practices, Environ. Int., 32, 983-995, 2006.

Houghton, J. D. R., Doyle, T. K., Davenport, J., and Hays, G. C.: Developing a simple, rapid method for identifying and monitoring jellyfish aggregations from the air, Mar. Ecol. Prog. Ser., 314, 159-170, 2006.

Howell, K. A., Achterberg, E. P., Braungardt, C. B., Tappin, A. D., Turner, D. R., and Worsfold, P. J.: The determination of trace metals in estuarine and coastal waters using a voltammetric in situ profiling system, Analyst, 128, 734-741, 2003.

Hu, C., Luerssen, R., Muller-Karger, F. E., Carder, K. L., and Heil, C. A.:. On the remote monitoring of Karenis brevis blooms of the west Florida shelf, Cont. Shelf Res., 28, 159-176, 2008.

Hu, C., Muller-Karger, F. E., Taylor, C., Carder, K. L., Kelble, C., Johns, E, and Heil, C.: Red tide detection and tracing using MODIS fluorescence data: A regional example in SW Florida coastal waters, Remote Sens. Environ., 97, 311-321, 2005.

ISO/IEC TR 15938-8: Information technology - Multimedia content description interface - Part 8: Extraction and use of MPEG-7 descriptions, 2002.

Jiang, S, Noble, R., and Chui, W. P.: Human adenoviruses and coliphages in urban runoff-impacted coastal waters of Southern California, Appl Environ. Microbiol., 67(1), 179-184, 2001.

Johnson, D. C., Enriquez, C. E., Pepper, I. L., Davis, T. L., Gerba, C. P, and Rose, J. B.: Survival of giardia, cryptosporidium, poliovirus and salmonella in marine waters, Water Sci. Technol., 35(11-12), 261-268, 1997.

Johnson, K. S. and Coletti, L. J.: In situ ultraviolet spectrophotometry for high resolution and long-term monitoring of nitrate, bromide and bisulfide in the ocean, Deep-Sea Res. I, 49, 1291-1305, 2002.

Johnson, K. S., Coletti, L. J., and Chavez, F. P.: Diel nitrate cycles observed with in situ sensors predict monthly and annual new production, Deep-Sea Res. I, 53, 561-573, 2006.

Kay, D., Fleisher, K. D., J. M., Salmon, R. L., Jones, F., Wyer, M. D., Godfree, A. F., Zelenauch-Jacquotte, Z., and Shore, R.: Predicting likelihood of gastroenteritis from sea bathing: results from randomized exposure, Lancet, 344(8927), 905-909, 1994.

Kirkpatrick, G. J., Millie, D. F., Moline, M. A., and Schofield, O.: Optical discrimination of a phytoplankton species in natural mixed populations, Limnol. Oceanogr., 45, 467-471, 2000.

Krock, B., Tillmann, U., John, U., and Cembella, A.: LC-MS-MS aboard ship: tandem mass spectrometry in the search for phycotoxins and novel toxigenic plankton from the North Sea, Anal. Bioanal. Chem., 392(5), 797-803, 2008.

Krock, B., Tillmann, U., John, U., and Cembella, A. D.: Characterization of azaspiracids in plankton size-fractions and isolation of an azaspiracid-producing dinoflagellate from the North Sea, Harmful Algae, 8, 254-263, 2009.

Kronfeldt, H.-D., Schmidt, H., Maiwald, M., Gallasch, L.-H., Konat-Stepowicz, J., Lehaître, M., LeNoac'h, A., Pfannkuche,
J., Amann, H., Szymczak-Zyla, M., Filipowska, A., Lubecki, L., Kowalewska, G., Esteban-Martínez, O., Navarrete, M.-C., Díaz-Herrera, N., González-Cano, A., Bernabeu, E., Gibson, C., Mac Craith, B., Leclercq, M., and Roussel, B.: Multiparametric in-situ Spectroscopic Measuring System for Costal Monitoring employed under field conditions in the Gulf of Gdansk, Proc. ISOPE, 433-37, 2004.

LaGier, M. J., Fell, J. W., and Goodwin, D.: Electrochemical detection of harmful algae and other microbial contaminant in coastal waters using hand-held biosensors, Mar. Poll. Bull., 54, 757-770, 2007.

Landis, W. G.: Twenty years before and hence; Ecological risk assessment of multiple scales with multiple stressors and multiple endpoints, Hum. Ecol. Risk Assess., 9, 1317-1326, 2003.

Larsen, L. H., Kjaer, T., and Revsbech, N. P.: A microscale No. 3-biosensor for environmental applications, Anal. Chem., 69, 3527-3531, 1997.

Latecki, L. J. and Lakämper, R.: Shape similarity measure based on correspondence of visual parts, IEEE Trans. Pattern Analysis and Machine Vision, 22(10), 1-6, 2000.

Lawton, L. A., Edwards, C., and Codd, G. A.: Extraction and highperformance liquid chromatographic method for the determination of microcystins in raw and treated waters, Analyst, 119, 1525-1530, 1994.

Liao, V. H.-C, Chien, M.-T., and Ou, K.-L.: Assessment of heavy metal bioavailability in contaminated sediments and soils using green fluorescent protein-based bacterial biosensors, Environ. Pollut., 142, 17-23, 2006.

Lieberzeit, P. A. and Dickert, F. L.: Sensor technology and its application in environmental analysis, Anal. Bioanal. Chem., 387, 237-247, 2007.

Liu, X., Wang, Z. A., Byrne, R. H., Kaltenbacher, E. A., and Bernstein, R. E.: Spectrophotometric measurements of $\mathrm{pH}$ in-situ: laboratory and field evaluations of instrumental performance, Environ. Sci. Technol., 40, 5036-5044, 2006.

Luo, T., Kramer, K., Goldgof, D., Hall, L., Samson, S., Remsen, A., and Hopkins, T., Recognizing plankton images from the Shadow Image Particle Profiling Evaluation Recorder, IEEE T. Sys. Man. Cyb., 34, 1753-1762, 2004.

Marr, J. C., Hu, T., Pleasance, S., Quilliam, M. A., and Wright, J. L. C.: Detection of new 7-O-acryl derivatives of diarrhetic shellfish poisoning toxins by liquid chromatography-mass spectrometry, Toxicon, 30(12), 1621-1630, 1992.

Masó, M. and Garcés, E.: Harmful microalgae blooms (HAB); problematic and conditions that induce them, Mar. Poll. Bull., 53, 620-630, 2006.

Maso, M., Garces, E., Pages, F., and Camp, J.: Drifting plastic debris as a potential vector for dispersing Harmful Algal Bloom (HAB) species, Scientia Marina, 67(1), 107-111, 2003.

Metfies, K. and Medlin, L. K.: Feasibility of transferring fluorescent in situ hybridization probes to an 18S rRNA gene Phylochip and mapping of signal intensities, Appl. Envir. Microbiol, 74, 28142821, 2008.

Millie, D. F., Schofield, O. M., Kirkpatrick, G. J., Johnsen, G., Tester, P. A., and Vinyard, B. T.: Detection of harmful algal blooms using photopigments and absorption signatures: A case study of the Florida red tide dinoflagellate, Gymnodinium breve, Limnol. Oceanogr., 42, 1240-1251, 1997.

Mills, C. E.: Jellyfish blooms: are populations increasing glob- 
ally in response to changing ocean conditions? Hydrobiologia, 451(1-3), 55-68, 2001.

Mitchell, B. G., Kahru, K., and Sherman, J., Autonomous temperature-irradiance profiler resolves the spring bloom in the Sea of Japan, Proceedings of Ocean Optics XV, 16-20 October, Monaco, Office Naval Research, USA, CD-ROM, 2000.

Moore, C., Barnard, A., Fietzek, P., Lewis, M. R., Sosik, H. M., White, S., and Zielinski, O.: Optical tools for ocean monitoring and research, Ocean Sci. Discuss., 5, 659-717, 2008, http://www.ocean-sci-discuss.net/5/659/2008/.

Murphy, T., Lucht, S., Schmidt, H., and Kronfeldt, H.-D.: Surfaceenhanced Raman scattering (SERS) system for continuous measurements of chemicals in seawater, J. Raman Spectrosc., 31, 943-948, 2000.

Nguyen, T. B. H.: Surface-enhanced Raman scattering (SERS) for in-situ analysis of mixture of polycyclic aromatic hydrocarbons (PAH) in seawater, Thesis, TU Berlin, D 83, 2004.

NOAA: Harmful Algal Bloom Forecasting System, online available at: www.csc.noaa.gov/crs/habf, 2008a.

NOAA: CoastWatch Program, online available at: http:// coastwatch.noaa.gov, 2008b.

NOAA: National Ocean Report. Ocean Observations, online available at: www.publicaffairs.noaa.gov/oceanreport/observations. html, 2008c.

Oehme, I. and Wolfbeis, O. S.: Optical sensors for determination of heavy metal ions, Mikrochim. Acta, 126, 177-192, 1997.

OJEC: Directive 2000/60/EC of the European Parliament and of the Council, of 23. October 2000, establishing a framework for Community action in the field of water policy, Official journal of the European communities, L327, 72 pp., 2000.

Olson, R. J., Shalapyonok, A., and Sosik, H. M.: An automated submersible flow cytometer for analyzing pico- and nanophytoplankton, Deep Sea Res., 50, 301-315, 2003.

OSPAR: Hazardous Substances, online available at: http: //www.ospar.org/content/content.asp?menu=00200304000000_ 000000_000000, 2009.

Parthuisot, N., Catala, P., Lemarchand, K., Baudart, J., and Lebaron, P.: Evaluation of Chemchrome V6 for bacterial viability assessment in waters, J. Appl. Microbiol., 89(2), 370-380, 2000.

Patterson, M. and Brescia, A.: Integrated sensor systems for UAS. Proceedings of the 23rd Bristol UAV Conference, April 2008, 13 pp., online available at: http://www.acrtucson.com/Presentations_n_Publications/pdf/ 23rd_Bristol_Sensors_Conf_07.pdf, last access: 28 August 2009, 2008.

Paul, J., Scholin, C., v. den Engh, G., and Perry, M. J.: A sea of microbes. In situ instrumentation, Oceanography, 20, 70-78, 2007.

Prien, R. D.: The future of chemical in situ sensors, Mar. Chem., 107, 422-432, 2007.

Prien, R. D., Connelly, D. P., and German, C. R.: In situ chemical analyser for the determination of dissolved $\mathrm{Fe}(\mathrm{II})$ and $\mathrm{Mn}(\mathrm{II})$, Ocean Sciences Meeting 2006, Honolulu, HI, USA, OS44B-06, 2006.

Prüss, A.: A review of epidemiological studies from exposure to recreational water. Int. J. Epidemiol., 27, 1-9, 1998.

Quilliam, M. A.: Chemical methods for lipophilic shellfish toxins, in: Manual on Harmful Marine Microalgae, edited by: Hallegraeff, G. M., Anderson, D. M., and Cembella, A. D., Monographs on Oceanographic Methodology, 11, 211-245, UNESCO, Paris,
2003.

Reinart, A. and Kutser, T.: Comparison of different satellite sensors in detecting cyanobacterial bloom events in the Baltic Sea, Remote Sens. Environ., 102(1-2), 74-85, 2006.

Remsen, A., Samson, S., and Hopkins, T.: What you see is not what you catch: a comparison of concurrently collected net, optical plankton counter and shadowed image particle profiling and evaluation recorder data from the northeast Gulf of Mexico, Deep Sea Res. I, 51, 129-151, 2004.

Rios, L. M., Moore, C., and Jones, P. R.: Persistent organic pollutants carried by synthetic polymers in the ocean environment, Mar. Poll. Bull., 54(8), 1230-1237, 2007.

Robbins, I. C., Kirkpatrick, G. J., Blackwell, S. M., Hillier, J., Knight, C. A., and Moline, M. A.: Improved monitoring of HABs using autonomous underwater vehicles (AUV), Harmful Algae, 5, 749-761, 2006.

Rohde, P., Busch, J. A., Henkel, R. H., Voss, D., and Zielinski, O.: Detection and identification of hydrocarbons in marine waters using time-resolved laser-fluorescence: Set-up and first results of a new submersible sensor, Proceedings of Oceans, 1-5, 2009.

Rossini, G. P.: Functional assays in marine biotoxin detection, Toxicology, 207, 451-462, 2005.

Rutten, T. P. A., Sandee, B., and Hofman, A. R. T.: Phytoplankton monitoring by high performance flow cytometry: A successful approach? Cytometry Part A, 64A(1), 16-26, 2005.

Ryan, P. G., Connell, A. D., and Gardner, B. D.: Plastic ingestion and PCBs in seabirds: Is there a relationship?, Mar. Poll. Bull, 19, 174-176, 1988.

Sakamoto, C. M. Johnson, K. S., and Coletti, L. J.: Improved algorithm for the computation of nitrate concentrations in seawater using an in situ ultraviolet spectrophotometer, Limnol. Oceanogr. Meth., 7, 132-143, 2009.

Schmidt, H., Bich Ha, N. Pfannkuche, J., Amann, H., Kronfeldt, H.-D., and Kowalewska, G.: Detection of PAHs in seawater using surface-enhanced Raman scattering (SERS), Mar. Poll. Bull., 49(3) 229-234, 2004.

Scholin, C. A.: What are "ecogenomic sensors?" - a review and thoughts for the future, Ocean Sci. Discuss., 6, 191-213, 2009, http://www.ocean-sci-discuss.net/6/191/2009/.

Scholin, C. A., Doucette, G. J., and Cembella, A. D.: Prospects for developing automated systems for in situ detection of harmful algae and their toxins, in: Real-Time Coastal Observing Systems for Ecosystem Dynamics and Harmful Algal Blooms, edited by: Babin, M., Roesler C. S., and Cullen, J. J., 413-462, UNESCO Publishing, Paris, France, 2008.

Scholin, C. A., Doucette, G. J., Jensen, S., Roman, B., Partett, D., Marin III, R., Jones, P. W., Feldman, J., Everlove, C., Harris, A., Alvarado, N., Massion, E., Birch, J., Greenfield, D., Vrijenhoek, R., Mikulski, C., and Jpnes, K.: Remote detection of marine microbes, small invertebrates, harmful algae and biotoxins using the Environmental Sample Processor (ESP), Oceanography, 22, 158-167, 2009.

Schulz, J., Mengedoht, D., Barz, K., Basilico, A., Henrich, M., and Hirche H.-J.: LOKI- Lightframe On-sight Keyspecies Investigation - Remote sensing of zooplankton, in: Observing the coastal sea - An Atlas of Advanced Monitoring techniques, edited by: Doerffer, R., Colijn, F., and van Beusekom, J., LOICZ Reports \& Studies No. 33 Geesthacht, Germany, GKSS Research Centre, ISSN 1383 4304, 2008. 
Sesay, A. M. and Cullen, D. C.: Detection of hormone mimics in water using a miniturised SPR Sensor, Environ. Monit. Assess., 70(1), 83-92, 2001.

Sieracki, C. K., Sieracki, M. E., and Yentsch, C. S.: An imagingin-flow system for automated analysis of marine microplankton, Mar. Ecol. Prog. Ser., 168, 285-296, 1998.

Solé, S., Merkoci, A., and Alegret, S.: Determination of toxic substances based on enzyme inhibition. Part II. Electrochemical biosensors for the determination of pesticides using flow systems, Crit. Rev. Anal. Chem., 33, 127-143, 2003.

Spangler, B. D., Wilkinson, E. A., Murphy, J. T., and Tyler, B. J.: Comparison of the Spreeta surface plasmon resonance sensor and a quartz crystal microbalance for the detection of Escherichia coli heat-labile enterotoxin, Anal. Chim. Acta, 444, 149-161, 2001.

Spear, A., Daly, K., Huffman, D., and Garcia-Rubio, L.: Progress in developing a new detection method for the harmful algal bloom species, Karenia brevis, through multiwavelength spectroscopy, Harmful Algae, 8(2), 189-195, 2009.

Steidinger, K. A., Landsberg, J. H., Tomas, C. R., and Burns, J. W.: Harmful Algal Blooms in Florida, unpublished technical report submitted to the Florida Harmful Algal Bloom Task Force, Florida Marine Research Institute, 683 pp., online available at: http://www.gomrc.org/docs/HAB_In_Florida_ March_1999.pdf, 1999.

Straub, T. M. and Chandler, D. P.: Towards a unified system for detecting waterborne pathogens, J. Microbiol. Meth., 53, 185197, 2003.

Stumpf, R. P.: Applications of satellite ocean color remote sensors for monitoring and predicting Harmful Algal Blooms, Human and Ecological Risk Assessment, 7(5), 1363-1368, 2001.

Stumpf, R. P., Culver, M. E., Tester, P. A., Tomlinson, M., Kirkpatrick, G. J., Pederson, B. A., Truby, E., Ransibrahmanakul, V., and Soracco, M.: Monitoring Karenia brevis blooms in the Gulf of Mexico using satellite ocean color imagery and other data, Harmful Algae, 2, 147-160, 2003.

Suri, C. R., Raje, M., and Varshney, G. C.: Immunosensors for pesticide analysis: antibody production and sensor development, Crit. Rev. Biotechnol., 22, 15-32, 2002.

Tarancón, A., García, J. F., and Rauret, G.: Development of a radiochemical sensor. Part I: Feasibility study, Anal. Chim. Acta, 538, 233-239, 2005

Taylor, S., Tindall, R. F., and Syms, R. R. A.: Silicon based quadrupole mass spectrometry using microelectromechanical systems, J. Vac. Sci. Technol. B, 19(2), 557-562, 2001.

Tercier, M.-L., Buffle, J., and Graziottin, F.: A novel voltammetric in situ profiling system for continuous real-time monitoring of trace elements in natural waters, Electroanalysis, 10, 355-363, 1998.

Tercier-Waeber, M.-L., Buffle, J., Confalonieri, F., Riccardi, G., Sina, A., Graziottin, F., Fiaccabrino, G. C., and Koudelka-Hep, M.: Submersible voltammetric probes for in situ trace element measurements in surface water, groundwater and sediment-water interface, Meas. Sci. Technol., 10, 1202-1213, 1999.

Tercier-Waeber, M.-L., Confalonieri, F., Riccardi, G., Sina, A., Nöel, S., Buffle, J., and Graziottin, F.: Multi Physical-chemical profiler for real-time in situ monitoring of trace metal speciation and master variables: Development, validation and field applications, Mar. Chem., 97, 216-235, 2005.
Tester, P. A., Shea, D., Kibler, S. R., Varnam, S. M., Black, M. D., and Litaker, R. W.: Relationships among water column toxins, cell abundance and chlorophyll concentrations during Karenia brevis blooms, Cont. Shelf Res., 28, 59-72, 2008.

Teuten, E. L., Rowland, S. J., Galloway, T. S., and Thompson, R. C.: Potential for plastics to transport hydrophobic contaminants, Environ. Sci. Technol., 41, 7759-7764, 2007.

Thompson, R. C., Olsen, Y., Mitchell, R. P., Davis, A., Rowland, S. J., John, A. W. G., McGonigle, D., and Russell, A. E.: Lost at sea: where is all the plastic?, Science, 304, p. 838, 2004.

Thyssen, M., Tarran, G. A., Zubkov, M. V., Holland, R. J., Grégori, G., Burkill, P. H., and Denis, M.: The emerge of automated highfrequency flow cytometry: revealing temporal and spatial phytoplankton variability, J. Plank. Res., 30, 333-343, 2008.

Tillmann, U., Elbrächter, M., Krock, B., John, U., and Cembella, A. D.: Azadinium spinosum gen. et sp. nov (Dinophyceae) identified as a primary producer of azaspiracid toxins, Eur. J. Phycol., 44(1), 63-79, 2009.

Tsabaris, C., Mallios, A., and Papathanasiou, E.: Instrumentation for underwater in-situ radon analysis, Sea Technol., 49(3), 2126, 2008a.

Tsabaris, C., Bagatelas, C., Dakladas, T., Papadopoulos, C. T., Vlastou, R., and Chronis, G. T.: An autonomous in situ detection system for radioactivity measurements in the marine environment, Appl. Radiat. Isotop., 66(10), 1419-1426, 2008 b.

Tschmelak, J., Proll, G., and Gauglitz, G.: Optical biosensor for pharmaceuticals, antibiotics, hormones, endocrine disrupting chemicals and pesticides in water: Assay optimization process for estrone as example, Talanta 65(2), 313-323, 2005.

UNEP: Guidance for a Global Monitoring Programme for persistent organic Pollutants. UNEP Chemicals, Geneva, Switzerland, 105 pp., 2004.

US Federal Water Pollution Control Act (Clean Water Act) of 1948 and its amendments (33 U.S.C. 1251-1376), 1948.

Verma, A., Uzun, O., Hu, Y., Hu, Y., Han, H.-S., Watson, N., Chen S., Irvine, D. J., and Stellacci, F.: Surface-structure-regulated cell-membrane penetration by monolayer-protected nanoparticles, Nature Materials, 7(7), 588-595, 2008.

Waldmann, C., Tamburri, M., Prien, R. D., and Fietzek, P.: Assessment of sensor performance, Ocean Sci. Discuss., 6, 1687-1716, 2009, http://www.ocean-sci-discuss.net/6/1687/2009/.

Wang, Z. A., Liu, X., Byrne, R. H., Wanninkof, R., Bernstein, R. E., Kaltenbacher, E. A., and Patten, J.: Simultaneous spectrophotometric flow-through measurements of $\mathrm{pH}$, carbon dioxide fugacity, and total inorganic carbon in seawater, Anal. Chim. Acta, 596, 23-36, 2007.

WHO: Guidelines for safe recreational-water environments, Volume 1: Coastal and fresh waters, 2001.

Wiebe, P. H. and Benfield, M. C.: From the Hensen net toward four-dimensional biological oceanography, Prog. Oceanogr., 56, 7-136, 2003.

Wedekind, Ch., Schilling, G., Grüttmüller, M., and Becker, K.: Gamma-radiation monitoring network at sea, Appl. Radiat. Isotop., 50, 733-741, 1999.

Wells, P. G., Depledge, M. H., Butler, J. N., Manock, J. J., and Knap, A. H.: Rapid toxicity assessment and biomonitoring of marine contaminants - exploiting the potential of rapid biomarker assays and microscale toxicity tests, Mar. Poll. Bull., 42(10), 799-804, 2001. 
WHO: Guidelines for safe recreational-water environments. Volume 1: Coastal and fresh waters, 2001.

Worden, A. Z., Seidel, M., Smriga, S., Wick, A., Malfatti, F., Bartlett, D., and Azam, F.: Trophic regulation of Vibrio cholerae in coastal marine waters, Environ. Microbiol., 8, 21-29, 2006.

Zielinski, O., Andrews, R., Göbel, J., Hanslik, M., Hunsänger, T., and Reuter, R.: Operational airborne hydrographic laser remote sensing. Lidar remote sensing of Land and Sea, edited by: Reuter, R., EARSeL Proceedings, 1, 53-60, 2001.

Zielinski, O.: Airborne pollution surveillance using multi-sensor systems, Sea Technol., 44 (10), 28-32, 2003.

Zielinski, O., Hengstermann, T., and Robbe, N.: Detection of oil spills by airborne sensors, in: Marine Surface Films, edited by: Gade, M., Hühnerfuss, H., and Korenowski, G. M., 255-271, Springer, 2006a.

Zielinski, O., Cembella, B., and Heuermann, R.: Bio-optical sensors onboard autonomous profiling floats. Proceedings of OMAE06: 25th International Conference on Offshore Mechanics and Artic Engineering, 4-9 June 2006 Hamburg, 1-5, 2006 b.
Zielinski, O., Fiedler, B., Heuermann, R., Körtzinger, A., Kopiske, E., Meinecke, G., and Munderloh, K.: A new nitrate continuous observation sensor for autonomous sub-surface applications: Technical design and first results. IEEE, Proceedings of the International Conference on Marine Challenges: From Coastline to Deep Sea, Aberdeen, 18-22 June 2007, 1-4, 2007.

Zielinski, O. and Brehm, R.: Hyperspectral multi-parameter sensing for marine environmental security, International Ocean Systems, 11(6), 19-21, 2007.

Zimmermann, U., Skrivanek, T., and Löhmannsröben, H. G.: Fluorescence quenching of polycyclic aromatic compounds by humic substances: Part 1. Methodology for the determination of sorption coefficients, J. Environ. Monit., 1, 525-32, 1999. 